\title{
Effects of Fis on Escherichia coli gene expression during different growth stages
}

\section{Correspondence \\ Robert Osuna \\ Osuna@albany.edu}

Received 29 March 2007

Revised 6 June 2007

Accepted 14 June 2007

\author{
Meranda D. Bradley, ${ }^{1}$ Michael B. Beach, ${ }^{2}$ A. P. Jason de Koning, ${ }^{1}$ \\ Timothy S. Pratt ${ }^{3}$ and Robert Osuna ${ }^{1}$
}

Fis is a nucleoid-associated protein in Escherichia coli that is abundant during early exponential growth in rich medium but is in short supply during stationary phase. Its role as a transcriptional regulator has been demonstrated for an increasing number of genes. In order to gain insight into the global effects of Fis on E. coli gene expression during different stages of growth in rich medium, DNA microarray analyses were conducted in fis and wild-type strains during early, mid-, late-exponential and stationary growth phases. The results uncovered 231 significantly regulated genes that were distributed over 15 functional categories. Regulatory effects were observed at all growth stages examined. Coordinate upregulation was observed for a number of genes involved in translation, flagellar biosynthesis and motility, nutrient transport, carbon compound metabolism, and energy metabolism at different growth stages. Coordinate down-regulation was also observed for genes involved in stress response, amino acid and nucleotide biosynthesis, energy and intermediary metabolism, and nutrient transport. As cells transitioned from the early to the late-exponential growth phase, different functional categories of genes were regulated, and a gradual shift occurred towards mostly down-regulation. The results demonstrate that the growth phase-dependent Fis expression triggers coordinate regulation of 15 categories of functionally related genes during specific stages of growth of an $E$. coli culture.

\section{INTRODUCTION}

In Escherichia coli, Fis (factor for inversion stimulation) is the most abundant nucleoid-associated protein (NAP) during the exponential growth phase in rapidly growing cultures (Ali Azam et al., 1999). In a process known as growth phase-dependent regulation, the intracellular Fis levels peak during early exponential growth at over 50000 molecules per cell, and thereafter decrease until they become very low during stationary phase (Ball et al., 1992; Finkel \& Johnson, 1992; Nilsson et al., 1992b). Several layers of regulatory control are in place to ensure that appropriate quantities of Fis are present in response to a

Abbreviations: CRP, cyclic AMP receptor protein; H-NS, histone-like nucleoid structuring protein; IHF, integration host factor; qRT-PCR, reverse transcriptase quantitative PCR; RNAP, RNA polymerase; WMW, Wilcoxon-Mann-Whitney; WT, wild type.

The array data discussed in this publication have been deposited in the NCBI Gene Expression Omnibus (GEO; http://www.ncbi.nlm.nih.gov/ $\mathrm{geo} /$ ) and are accessible through provisional GEO series accession number GSE7398. range of nutritional environments and perhaps various other environmental signals. For example, fis transcription is negatively regulated by the stringent response in various enteric bacteria (Mallik et al., 2004; Ninnemann et al., 1992; Walker et al., 1999). Also, fis is subject to growth rate control (Ball et al., 1992; Mallik et al., 2006; Nilsson et al., 1992b). Growth phase-dependent regulation, stringent control and growth rate control all require the transcriptional factor DksA (Mallik et al., 2006). An additional layer of Fis regulation, involving the ribosome binding protein BipA, occurs at the level of translation (Owens et al., 2004).

Fis was originally identified as a factor required to stimulate the site-specific DNA inversion reactions mediated by the Hin, Gin and Cin family of DNA recombinases (Haffter \& Bickle, 1987; Johnson et al., 1986; Kahmann et al., 1985). Subsequently, it was found to be engaged in other site-specific DNA recombination processes (Ball \& Johnson, 1991; Thompson et al., 1987; Weinreich \& Reznikoff, 1992), to alter DNA supercoiling (Schneider et al., 1997, 2001; Skoko et al., 2005; Travers et al., 2001), to influence the initiation of DNA replication 
(Filutowicz et al., 1992; Messer et al., 1991; Ryan et al., 2004; Wold et al., 1996; Wu et al., 1996), and to regulate a growing number of genes directly or indirectly (Ball et al., 1992; Bosch et al., 1990; Gonzalez-Gil et al., 1996; Green et al., 1996; Jacobson \& Fuchs, 1998; Keane \& Dorman, 2003; Pease et al., 2002; Ross et al., 1990; Shin et al., 2003; Xu \& Johnson, 1995a, c). Prominent among these regulated genes are the rRNA and various tRNA genes, which are directly stimulated by Fis (Bosch et al., 1990; Hirvonen et al., 2001; Nilsson \& Emilsson, 1994; Ross et al., 1990). In the case of the $r r n B \mathrm{P} 1$ promoter, Fis resembles a class I transcription activator that interacts with the C-terminal domain of the $\alpha$ subunit ( $\alpha$ CTD) of RNA polymerase (RNAP) from a binding site at -71 (Bokal et al., 1997; Gosink et al., 1996; Zhi et al., 2003). In the case of the RpoS-dependent proP P2 promoter, Fis acts more like a class II transcription activator that contacts $\alpha$ CTD from a binding site at -41 (McLeod et al., 1999, 2002). In the leuV promoter, stimulation occurs in part by a Fis-mediated translocation of superhelical energy from upstream binding sites to the promoter region (Opel et al., 2004). Moreover, in the $t y r T$ promoter, Fis facilitates sequential steps during the transcription initiation process (Muskhelishvili et al., 1997). Thus, Fis functions as a versatile transactivator that functions at many different promoters. As a repressor, the functional binding sites of Fis can occur over a broader range of positions relative to the promoter than activator binding sites (Ball et al., 1992; Browning et al., 2000, 2004b; Caramel \& Schnetz, 2000; Gonzalez-Gil et al., 1998; Xu \& Johnson, 1995b), potentially resulting in a greater number of negatively regulated genes.

Most studies implicating Fis as a gene regulator have focused on a single gene at a time and often during the mid-exponential growth phase. In this study we set out to obtain a comprehensive profile of Fis-regulated genes in $E$. coli during various stages of growth in rich medium. A DNA microarray approach was used to examine the effect of Fis-dependent gene regulation on a genomic scale, which showed that the expression of 231 genes was significantly altered during one or more growth stages. These genes were classified into 15 different functional categories, demonstrating the broad physiological influence of Fis. Coordinate regulation of functionally related genes was observed during specific stages of growth, suggesting that Fis regulates related biological processes in step with the growth phase.

\section{METHODS}

Chemicals, enzymes, growth media and strains. Chemicals were purchased from Sigma-Aldrich, Invitrogen Life Technologies, Fisher Scientific, Bio-Rad Laboratories and Pharmco Products. Enzymes were purchased from New England Biolabs, Roche Pharmaceuticals, Ambion and United States Biochemical. RNase inhibitor, SYBR Green Master Mix and MultiScribe reverse transcriptase were from Applied Biosystems. Radioisotopes were from Amersham Biosciences. The bacterial growth media were from Difco Laboratories. The E. coli K12 strains used in the DNA microarray, reverse transcriptase quantitative PCR (qRT-PCR) and most Northern blot analyses were MC1000 [araD139, $\Delta$ (ara-leu) $7697 \Delta$ lacX74 galU galK rpsL] (from M. Casadaban, University of Chicago), commonly used as a wild type (WT) in numerous studies, and MC1000 fis:: kan (Johnson et al., 1988). MG1655 (ilvG rfb-50 rph-1) and MG1655 fis:: kan (from R. C. Johnson, UCLA) were used only in the Northern blot analysis of prfC. Cells were grown in Luria-Bertani (LB) medium at $37{ }^{\circ} \mathrm{C}$, with constant agitation. Cultures of MC1000 fis::kan strains were supplemented with $50 \mu \mathrm{g}$ kanamycin $\mathrm{ml}^{-1}$. We note that while exposure of antibiotic-sensitive strains to low concentrations of certain kinds of antibiotics can affect the expression of a number of genes in E. coli, such effects are largely suppressed or undetected in antibiotic-resistant strains (Goh et al., 2002). Hence, the presence of kanamycin in cultures of MC1000 fis:: kan should have minimal or undetectable effects on gene regulation.

RNA preparation. Saturated E. coli cultures were diluted in LB to a density corresponding to $\mathrm{OD}_{600} 0.05$ and grown at $37^{\circ} \mathrm{C}$. Cells were harvested at various times during growth, and total cellular RNA was prepared using the hot acid phenol extraction method, as described by Aiba et al. (1981), or the MasterPure RNA Purification kit (EPICENTRE Technologies). The 23S RNA : 16S RNA signal ratios in the RNA samples were examined using electrophoresis on a $1 \%$ polyacrylamide gel and the Agilent Bioanalyser system (Agilent Technologies). Primer extension assays were also performed to verify the differential fis mRNA expression between WT and fis strains.

DNA microarray processing. Affymetrix Antisense E. coli DNA microarrays (Affymetrix) were processed at the University of Rochester Microarray Core Facility or the University at Albany Center for Functional Genomics. Synthesis of cDNA from $10 \mu \mathrm{g}$ RNA samples was performed using random hexameric primers, and followed by DNase I catalysed fragmentation to yield 50-100 bp fragments. The fragmented cDNA was labelled with an Enzo BioArray Terminal Labeling kit (Affymetrix) according to the manufacturer's specifications. Microarray hybridization, streptavidin-phycoerythrin (SAPE; Molecular Probes) staining, and washing were performed in the Affymetrix fluidics module following manufacturer's procedures. Detection and quantification of target hybridization were performed with a GeneArray Scanner 2500 (Hewlett Packard/Affymetrix). Various concentrations of control transcripts were spiked into the hybridization cocktail and their relative signal intensities monitored to assess array performance.

Three independent experiments were performed with MC1000 and MC1000 fis strains. Each experiment consisted of samples taken at different times during growth: $90 \mathrm{~min}$ (early exponential phase), $150 \mathrm{~min}$ (mid-exponential phase), $240 \mathrm{~min}$ (late-exponential phase) and 360 min (early stationary phase). The raw data was analysed using Microarray Analysis Suite version 5.0 (Affymetrix). The data for each stage of growth were normalized, merged and filtered by standard deviation using GeneSpring 7 (Agilent Technologies). The resulting signals showing twofold regulation or greater were subjected to one-way analysis of variance (ANOVA) using a cross-gene error model. All DNA microarrays used in this work comply with the MIAME guidelines (Brazma et al., 2001), and the complete dataset has been deposited in the GEO online database under the provisional accession number GSE7398.

Functional categories enriched for Fis-regulated genes. Functional categories enriched for Fis-regulated genes at each time of growth were determined by performing Wilcoxon-Mann-Whitney (WMW) tests (Sokal \& Rohlf, 1995) on the distribution of $P$ values for regulation, using the functional category assignments supplied by Affymetrix and the $\mathrm{R}$ statistical programming language (Grunsky, 2002; Ikaka \& Gentleman, 1996). The $P$ value distributions were based on one-way ANOVA between WT and fis treatments as implemented 
in GeneSpring, using a cross-gene error model to approximate the variance in expression ratios per gene. The WMW test assesses whether the distribution of $P$ values for regulation in each functional category is significantly enriched $(P \leqslant 0.05)$ for low $P$ values as compared to the entire distribution over all functional categories.

qRT-PCR. qRT-PCR was performed in the Molecular Biology Core Facilities of the Center for Functional Genomics, University at Albany. Primer pair sets for specific genes (Integrated DNA Technologies) were selected with Primer Express software (version 2.0, Applied Biosystems). Either one-step (Applied Biosciences) or two-step qRT-PCR reactions (Ambion) were performed according to manufacturer specifications to quantify gene expression. Reactions lacking template RNA or cDNA were included as negative controls.

Reaction plates were processed on an Applied Biosystems 7900HT Sequence Detection System. For one-step assays, the reversetranscription reaction was performed at $48{ }^{\circ} \mathrm{C}$ for $30 \mathrm{~min}$. Subsequently, the AmpliTaq Gold polymerase was activated at $95{ }^{\circ} \mathrm{C}$ for $10 \mathrm{~min}$, followed by 40 cycles consisting of denaturation for $15 \mathrm{~s}$ at $95{ }^{\circ} \mathrm{C}$ and annealing and extension for $60 \mathrm{~s}$ at $60{ }^{\circ} \mathrm{C}$. For two-step assays, the iTaq polymerase (Bio-Rad Laboratories) was activated at $95{ }^{\circ} \mathrm{C}$ for $2.5 \mathrm{~min}$, followed by the same 40 cycles described above. Amplification data were analysed with ABI Prism SDS 2.1 software (Applied Biosystems). Relative quantification of gene expression was performed by the $\Delta \Delta \mathrm{C}_{\mathrm{t}}$ method (Winer et al., 1999), using 16S rRNA as an endogenous control for normalization. All reactions were performed in triplicate and SDs were less than $12 \%$ of the mean.

Northern blot hybridizations. Northern blots were performed as described by Sambrook et al. (1989). The ${ }^{32} \mathrm{P}$-labelled DNA probes were generated by PCR in the presence of $\left[\alpha-{ }^{32} \mathrm{P}\right] \mathrm{dATP}$ $\left(>3000 \mathrm{Ci} \mathrm{mmol}^{-1}\right.$; >111 $\mathrm{TBq}_{\mathrm{mmol}}^{-1}$ ) using chromosomal DNA as template and oligonucleotides complementary to the gene of interest. Hybridizations were performed at $42{ }^{\circ} \mathrm{C}$ using a $50 \%$ formamide solution, as described by Sambrook et al. (1989). Detection and quantification of signals were performed using a Storm 860 PhosphorImager and ImageQuant software version 1.2 (Molecular Dynamics).

Identification of potential Fis binding sequences. Potential Fis binding sequences in the region from -300 to +20 relative to the first codon in the genes or operons reported by the DNA microarray analysis were retrieved using the Regulatory Sequence Analysis Tools (http://rsat.ulb.ac.be). A symmetrical weight matrix used in this analysis was assembled by using the nucleotide frequencies in both DNA strands of 60 experimentally defined Fis binding sites for a total of 120 bases per position (Hengen et al., 1997). We limited the matrix (Table 1) to 19 positions, which include a central region of 15 positions representing the core Fis DNA binding sequence (Feng et al., 1992; Finkel \& Johnson, 1992) plus two additional positions on either side. The numbers represent the frequency of each base (indicated on the left) at each position.

Table 1. Weight matrix for Fis binding sites

Numbers represent the frequency of each base (indicated in bold type on the left) at each position in 120 sequences representing Fis binding sites.

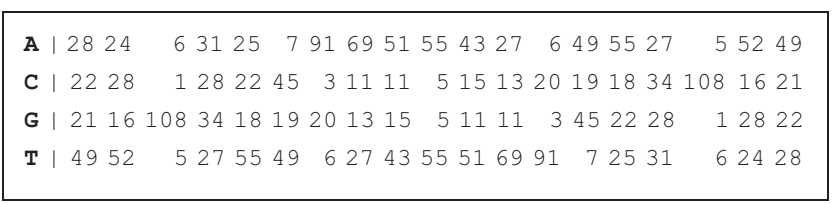

\section{RESULTS}

\section{RNA sampling}

The MC1000 fis::kan strain carries a neomycin cassette replacing about two-thirds of the internal fis sequence (Fig. 1a) (Johnson et al., 1988). MC1000 (WT) and MC1000 fis:: kan (fis) strains were grown in LB medium at $37{ }^{\circ} \mathrm{C}$. Samples were removed from both strains for total RNA preparation after $90 \mathrm{~min}$ (early exponential), $150 \mathrm{~min}$ (mid-exponential), $240 \mathrm{~min}$ (late exponential) and $360 \mathrm{~min}$ (stationary phase) (Fig. 1b). The negative fis autoregulation and growth phase-dependent fis mRNA expression pattern (Ball et al., 1992; Ninnemann et al., 1992) were verified in these RNA samples using a primer

(a)

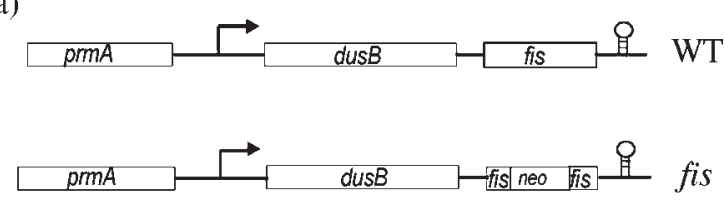

(b)

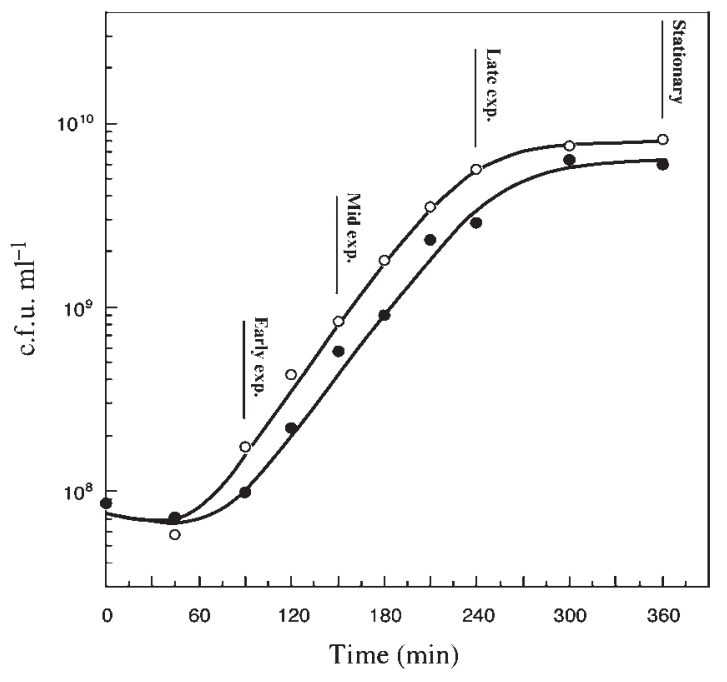

Fig. 1. RNA sampling in $\mathrm{MC} 1000$ and $\mathrm{MC} 1000$ fis : : kan during growth in LB medium. (a) Schematic representation of the fis operon. Rectangles represent ORFs. The fis operon transcribed by a single promoter (arrow) consists of two genes, dus $B$ and fis, and is preceded by prmA in E. coli. The lower portion shows the fis operon with a central region of fis replaced by a neomycin cassette (neo) in MC1000 fis::kan. (b) Period of growth sampled for Fisdependent gene expression. Saturated cultures of MC1000 $(\bigcirc)$ and $\mathrm{MC1000}$ fis::kan (๑) were diluted to $\mathrm{OD}_{600} 0.05$ in LB media and grown at $37{ }^{\circ} \mathrm{C}$. At various times during growth, c.f.u. $\mathrm{ml}^{-1}$ was determined. The stages at which cells were harvested for RNA isolation are indicated. The $\mathrm{OD}_{600}$ readings for $\mathrm{MC} 1000$ at the harvested times were 0.42 (90 $\mathrm{min}), 1.15$ (150 $\mathrm{min}), 2.7$ (240 $\mathrm{min}$ ) and 3.43 (360 $\mathrm{min})$; for MC1000 fis:: $k a n$ the $\mathrm{OD}_{600}$ readings were 0.29 (90 $\left.\mathrm{min}\right), 0.76$ (150 $\mathrm{min}), 2.64$ (240 $\mathrm{min}$ ) and 3.36 (360 $\mathrm{min})$. 
extension assay (not shown). The growth rate of the fis strain $\left(\mu=1.94\right.$ doublings $\left.\mathrm{h}^{-1}\right)$ was slightly slower than that of the WT $\left(\mu=2.14\right.$ doublings $\left.\mathrm{h}^{-1}\right)$, but the fis strain saturated at a lower cell density $\left(5.3 \times 10^{9}\right.$ cells $\left.\mathrm{ml}^{-1}\right)$ than

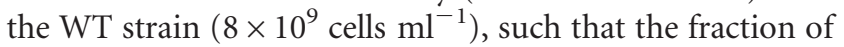
cell density saturation was very similar for both strains at each of the growth stages examined. Hence, the four growth stages examined were comparable between the two strains.

\section{Global effects of Fis on gene expression}

Microarray analysis of triplicate experiments showed that 231 genes had a significant $(P \leqslant 0.1)$ difference in expression (twofold or greater) between the WT and fis strains at one or more stages of growth (Table 2). Of these genes, 86 were more highly expressed in the presence of Fis and 158 were more highly expressed in the absence of Fis. Dual regulation was observed for 13 of these genes, i.e. relatively higher expression in the presence of Fis compared to its absence was detected in one growth stage, while lower expression was detected in another growth stage. Among the 231 genes, 137 belonged to 74 operons and 94 were single genes, suggesting that at least 168 different promoters were directly or indirectly targeted for Fis regulation. These results emphasize the global generegulatory function of Fis in E. coli, with $\sim 5 \%$ of the 4425 represented E. coli genes significantly differentially expressed in the presence compared to the absence of Fis. In addition, substantial RNA regulation was observed in intergenic regions (not shown), suggesting an involvement of Fis in regulating synthesis of non-coding RNAs.

\section{Validation of the results from DNA microarrays}

There are 18 genes in Table 2 which have been shown to be regulated by Fis in earlier work conducted in various laboratories (Ball et al., 1992; Browning et al., 2004a, 2005; Emilsson \& Nilsson, 1995; Gonzalez-Gil et al., 1996; Green et al., 1996; Nilsson \& Emilsson, 1994; Ninnemann et al., 1992; Xu \& Johnson, 1995b, c). In every case, the regulatory effects reported in the microarrays are consistent with those reported before. To further evaluate the results of our DNA microarray analysis, we performed qRT-PCR and determined the relative RNA expression of 15 genes from different operons in this list (Fig. 2). These genes fell into eight different categories and showed regulation in the microarrays during different stages of exponential growth. Two of the 15 selected genes (lctP and $y f i D$ ) exhibited dual regulation and were validated at the two corresponding periods of growth. The results from the qRT-PCR confirmed the positive or negative Fis-regulatory trend in 16 of 17 cases (Fig. 2). The only qualitative discrepancy observed was with fruK at $240 \mathrm{~min}$ of growth. An independent method of analysis will be required to resolve this contradictory effect.

The negative regulation of two additional genes seen in the microarray experiments ( $d n i R$ and $p r f C$ ) was validated by Northern blotting (Fig. 3). A strong negative regulation of
dniR (encoding a membrane-bound murein transglycosylase) was observed after 90 min of growth of MC1000. Negative regulation of $\operatorname{prfC}$ (encoding the peptide chain release factor RF3) was observed during the early exponential growth phase (after $60-120 \mathrm{~min}$ of growth). The latter was observed in MG1655 and MG1655 fis:: kan strains instead of the MC1000 and MC1000 fis strains used in the DNA microarray analysis, indicating that this regulatory effect is not strain-dependent.

Genes within the same operon are often co-regulated. We found that 102 of the 231 regulated genes identified in the microarray analysis formed part of an operon with one or more other genes in our list. In every case we observed that the genes pertaining to the same operon exhibited the same regulatory trend, indicating a strong consistency within the DNA microarray data.

The 231 regulated genes represent a conservative number. It excludes the seven rRNA operons, as their excessively strong hybridization signals in the microarray caused their quantification to be unreliable. Another 41 operons or single genes previously shown to be stimulated by Fis were not present among the regulated genes in Table 2. Without using a cross-gene error model, a number of genes not included in our list in Table 2 show twofold or greater regulation in the microarray data, with a $t$ test $P$ value $\leqslant 0.05$ in at least one of the time points sampled. Examples are $c y o A$ (encoding subunit II of cytochrome bo oxidase) and $f l g M$ (encoding $\sigma 28$ anti-sigma factor), which showed 3.17 -fold and 2.69-fold stimulation by Fis, respectively, during the early exponential growth phase. Northern blot analysis confirmed the positive regulation of these genes during the early and mid-exponential growth phases (Fig. 3).

\section{Functional categorization of Fis-regulated genes}

The 231 regulated genes involve a broad spectrum of cellular functions, which can be grouped into 15 categories (Fig. 4a). Among the most highly represented functional categories (containing from 19 to 39 genes and representing from 10 to $16 \%$ of the genes in each category) are (1) energy metabolism, (2) transport and membrane binding proteins, (3) translation, (4) cell processes (including adaptation and protection) and (5) central intermediary metabolism. Other functional categories containing six to 12 regulated genes and representing from 3 to $11 \%$ of the genes in each category are (6) cell structure, (7) carbon compound catabolism, (8) amino acid biosynthesis and metabolism, (9) nucleotide biosynthesis and metabolism, and (10) putative enzymes. Whereas 36 regulated genes fell under the (11) 'hypothetical, unclassified, unknown' category, this represented only $2 \%$ of the total genes in this category. To determine if any of these categories were significantly enriched for Fis-regulated genes, we performed WMW tests on the distribution of $P$ values for the Fis-dependent regulation of 4425 genes across 29 functional categories represented. The results showed that 14 functional categories were significantly enriched $(P \leqslant 0.05)$ 
Table 2. DNA microarray analysis of $E$. coli gene expression in the presence or absence of Fis

\begin{tabular}{|c|c|c|c|c|c|c|}
\hline \multirow[t]{2}{*}{ Functional category } & \multirow[t]{2}{*}{ Gene $^{*}$} & \multirow[t]{2}{*}{ Operon } & \multicolumn{4}{|c|}{ Time of growth [fold regulation $(P$ value $)] \dagger$} \\
\hline & & & $90 \mathrm{~min}$ & $150 \mathrm{~min}$ & $240 \mathrm{~min}$ & $360 \mathrm{~min}$ \\
\hline \multirow{9}{*}{$\begin{array}{l}\text { Amino acid biosynthesis and } \\
\text { metabolism }\end{array}$} & $a n s B$ & & & & $-14.28(<0.01)$ & \\
\hline & $c y s K$ & & & & $-2.08(0.03)$ & \\
\hline & hisH & hisG-I & & & $-3.03(0.08)$ & \\
\hline & $i a a A$ & & & & $-4.76(0.10)$ & \\
\hline & $t d c B$ & $t c d A-G$ & & & $-2.85(<0.01)$ & \\
\hline & tnaA & tnaCAB & & $-2.50(0.02)$ & & \\
\hline & $\operatorname{trp} A$ & $\operatorname{trpECDBA}$ & & & $-2.95(0.05)$ & \\
\hline & $\operatorname{trp} B$ & $\operatorname{trpECDBA}$ & & & $-2.98(0.02)$ & \\
\hline & $w r b A$ & $w r b A-y c c J$ & & & $-2.98(0.05)$ & \\
\hline \multirow{2}{*}{$\begin{array}{l}\text { Biosynthesis cofactors, } \\
\text { prosthetic groups and } \\
\text { carriers }\end{array}$} & bioF & bioBFCD & $-4.03(0.02)$ & & & \\
\hline & $\operatorname{grx} B$ & & & & $-2.27(0.06)$ & \\
\hline \multirow{11}{*}{$\begin{array}{l}\text { Carbon compound } \\
\text { catabolism }\end{array}$} & ald $B \ddagger$ & & & & $-3.22(0.07)$ & \\
\hline & fruA & fruBKA & & & $2.07(<0.01)$ & $3.19(<0.01)$ \\
\hline & fucO & fucAO & & & $-2.22(0.05)$ & \\
\hline & $g l c C$ & & & $-6.25(0.08)$ & & \\
\hline & $\underline{g l c G}$ & glcDEFGBA & & $2.43(0.03)$ & $-2.50(0.03)$ & \\
\hline & $\overline{k d g K}$ & & & $2.24(0.02)$ & $2.38(0.02)$ & $2.04(0.07)$ \\
\hline & $k d u I$ & $k d u I D$ & $4.77(0.01)$ & $3.61(0.01)$ & $3.39(<0.01)$ & $4.59(<0.01)$ \\
\hline & malM & malK-malM & $8.77(0.01)$ & & & \\
\hline & $\underline{\text { malP }}$ & malPQ & $9.59(0.02)$ & & $-2.77(0.04)$ & \\
\hline & $\overline{m a l Q}$ & malPQ & $5.65(0.02)$ & & & \\
\hline & treC & $\operatorname{tre} B C$ & $3.40(0.02)$ & & & \\
\hline \multirow{27}{*}{$\begin{array}{l}\text { Cell processes (including } \\
\text { adaptation and protection) }\end{array}$} & $a m p D$ & $a m p D E$ & & & $-2.86(0.08)$ & \\
\hline & cheW & motA-cheW & & $10.39(0.07)$ & & $6.10(0.09)$ \\
\hline & $\operatorname{csp} I$ & & & $-3.70(0.01)$ & & \\
\hline & $\operatorname{csp} F$ & & & $-2.04(0.03)$ & & \\
\hline & $e m r B$ & emrRAB & & & $-2.08(0.05)$ & \\
\hline & $f l g B$ & flgB-J & & & $2.33(0.09)$ & \\
\hline & flgI & $f l g B-J$ & & & $4.78(0.03)$ & \\
\hline & $f l g L$ & flgKL & & $5.93(0.09)$ & $2.24(0.01)$ & \\
\hline & fliJ & $f l i F-K$ & & $2.89(0.07)$ & $2.14(0.07)$ & \\
\hline & $\operatorname{gadC}$ & $\operatorname{gadBC}$ & & & $-3.22(0.06)$ & \\
\hline & $\operatorname{gadE}$ & & & & $-5.55(<0.01)$ & $-2.77(0.01)$ \\
\hline & hdeA & $h d e A B$ & & & $-3.70(0.02)$ & \\
\hline & $h d e B$ & $h d e A B$ & & & $-4.16(<0.01)$ & $-2.32(<0.01)$ \\
\hline & hlyE & & & & $-4.54(0.01)$ & \\
\hline & $i v y$ & & & & $-3.85(0.03)$ & \\
\hline & katE & & & & $-3.33(0.02)$ & \\
\hline & kat $G$ & katG-yijE & & & $-3.12(<0.01)$ & \\
\hline & $\operatorname{mot} A$ & motA-cheW & & $9.58(0.08)$ & $2.55(0.06)$ & $10.30(0.09)$ \\
\hline & $m o t B$ & motA-cheW & & & $2.83(0.10)$ & $11.14(0.09)$ \\
\hline & $m s r A$ & & & & $-2.78(0.02)$ & \\
\hline & osm $Y$ & & & & $-2.32(0.04)$ & \\
\hline & sodC & & & & $-3.12(<0.01)$ & $2.34(<0.01)$ \\
\hline & $\overline{\operatorname{tag}}$ & & & & $-2.94(0.07)$ & \\
\hline & $\operatorname{trg}$ & & & $2.43(0.09)$ & $2.19(0.02)$ & \\
\hline & uspe & & & & $-2.44(0.03)$ & \\
\hline & $u s p G$ & & & & $-2.70(0.01)$ & \\
\hline & $y k g C$ & & & & $-2.49(0.04)$ & \\
\hline \multirow[t]{4}{*}{ Cell structure } & flhA & $f \operatorname{lh} B A E$ & & $2.43(0.01)$ & & \\
\hline & fliH & fliF-K & & $2.17(0.09)$ & & \\
\hline & fliM & fliL-R & & & $2.70(0.09)$ & \\
\hline & fliN & $f l i L-R$ & & $2.95(0.06)$ & $2.35(0.04)$ & \\
\hline
\end{tabular}


Table 2. cont.

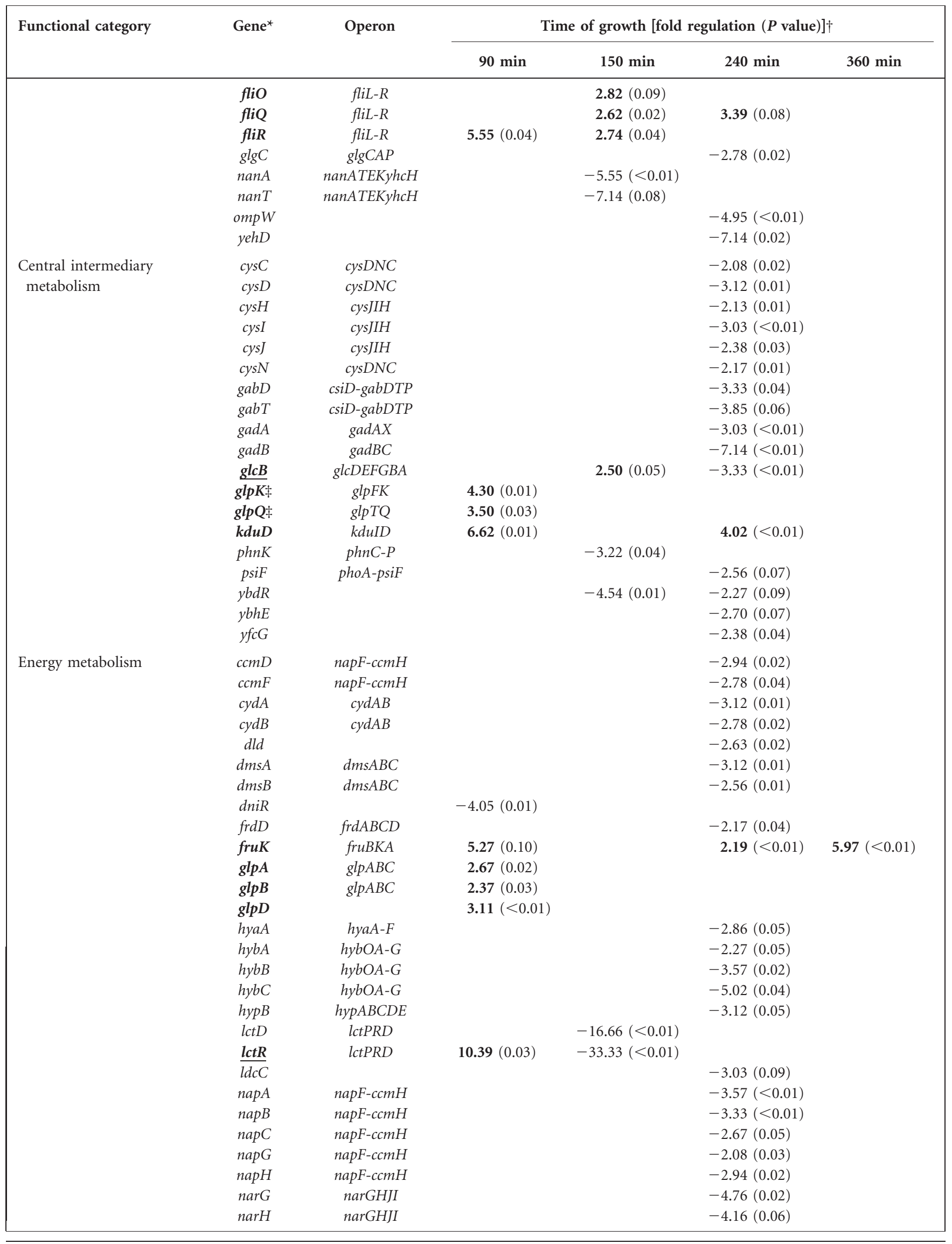


Table 2. cont.

\begin{tabular}{|c|c|c|c|c|c|c|}
\hline \multirow[t]{2}{*}{ Functional category } & \multirow[t]{2}{*}{ Gene $^{*}$} & \multirow[t]{2}{*}{ Operon } & \multicolumn{4}{|c|}{ Time of growth [fold regulation $(P$ value $)] \dagger$} \\
\hline & & & $90 \mathrm{~min}$ & $150 \mathrm{~min}$ & $240 \mathrm{~min}$ & $360 \mathrm{~min}$ \\
\hline \multirow{13}{*}{$\begin{array}{l}\text { Fatty acid and phospholipid } \\
\text { metabolism }\end{array}$} & narI & narGHJI & & & $-5.26(0.04)$ & \\
\hline & narJ & narGHJI & & & $-2.50(0.10)$ & \\
\hline & $n d h \neq$ & & & $2.98(0.09)$ & & \\
\hline & nirB $\ddagger$ & $\operatorname{nirB}-c y s G$ & & & $-6.25(<0.01)$ & \\
\hline & $\operatorname{nir} C \ddagger$ & $\operatorname{nirB}-c y s G$ & & & $-6.67(0.01)$ & \\
\hline & $\operatorname{nir} D \ddagger$ & $\operatorname{nirB}-c y s G$ & & & $-7.69(<0.01)$ & \\
\hline & $n r f A \ddagger$ & $n r f A B C D E F G$ & & & $-2.52(0.06)$ & \\
\hline & $n r f B \ddagger$ & $n r f A B C D E F G$ & & & $-2.44(0.01)$ & \\
\hline & $n r f C \ddagger$ & $n r f A B C D E F G$ & & & $-2.38(0.01)$ & \\
\hline & $p f l B$ & focApflB & & & $-2.27(0.05)$ & \\
\hline & $y f i D$ & & & $7.33(0.08)$ & $-3.03(0.01)$ & \\
\hline & $f a d B$ & $f a d B A$ & & & $3.12(0.06)$ & \\
\hline & $\operatorname{prpD}$ & $\operatorname{prpBCDE}$ & & $4.68(0.02)$ & & \\
\hline \multirow{36}{*}{$\begin{array}{l}\text { Hypothetical, unclassified, } \\
\text { unknown }\end{array}$} & $f l x A$ & & & & $2.48(0.05)$ & \\
\hline & paaA & & & $-11.11(0.02)$ & & $2.03(0.09)$ \\
\hline & poxA & & $-2.94(0.01)$ & & & \\
\hline & $t d c G$ & $t d c A-G$ & & & $-2.17(0.07)$ & \\
\hline & yaaH & & $-2.17(0.01)$ & & & \\
\hline & $y b e Q$ & & & $-6.25(0.03)$ & & \\
\hline & $y b f A$ & & $-2.56(0.07)$ & & & \\
\hline & $y b g E$ & & & & $-2.04(0.08)$ & \\
\hline & $y c a O$ & & $-2.08(0.02)$ & & & \\
\hline & $y c c J$ & $w r b A-y c c J$ & & & $-3.45(0.01)$ & \\
\hline & $y \operatorname{cgB} B$ & & & & $-2.94(0.02)$ & \\
\hline & $y d i F$ & & & & $2.13(0.08)$ & \\
\hline & yeaD & & & & $-2.63(0.01)$ & \\
\hline & yeaG & yeaGH & & & $-3.03(0.05)$ & \\
\hline & yeaH & yeaGH & & & $-2.27(0.09)$ & \\
\hline & yeaO & & & & $-2.08(0.08)$ & \\
\hline & yeeD & & $-3.70(0.08)$ & & & \\
\hline & yeiP & & & $2.00(0.04)$ & $2.03(0.03)$ & \\
\hline & yegD & & $-3.45(0.08)$ & & & \\
\hline & yfeT & & & $-2.22(0.03)$ & & \\
\hline & $y f h L$ & & $-2.51(<0.01)$ & & & \\
\hline & ygaF & $c s i D-g a b D T P$ & & $-3.45(0.10)$ & $2.23(0.08)$ & \\
\hline & $\overline{y g a M}$ & & & & $-2.04(0.10)$ & \\
\hline & $y h h A$ & & & & $-2.27(0.04)$ & \\
\hline & yiaI & & & & $-3.12(0.05)$ & \\
\hline & $y j c B$ & & $-4.35(<0.01)$ & & & \\
\hline & $y j c Z$ & & & $2.64(0.09)$ & & \\
\hline & yjgK & & & & $2.17(0.01)$ & $2.82(0.01)$ \\
\hline & $y j h B$ & $y j h B C$ & & $-14.28(0.01)$ & $-3.85(0.08)$ & \\
\hline & $y j i D$ & & & & $-4.17(0.01)$ & \\
\hline & $y j i Y$ & & $3.89(<0.01)$ & & & \\
\hline & $y l i G$ & & $-3.22(0.04)$ & & & \\
\hline & yohC & & & & $-5.55(0.01)$ & \\
\hline & $y p h A$ & & & & $-2.38(0.03)$ & \\
\hline & $y q j D$ & $y q j D E$ & & & $-3.12(0.03)$ & \\
\hline & $y q j E$ & $y q j D E$ & & & $-3.22(0.07)$ & \\
\hline \multirow{5}{*}{$\begin{array}{l}\text { Nucleotide biosynthesis and } \\
\text { metabolism }\end{array}$} & carA & $\operatorname{car} A B$ & & $2.33(0.09)$ & & \\
\hline & $g p t$ & & $-2.13(0.07)$ & & & \\
\hline & guaB & guaBA & $-2.56(0.07)$ & & & \\
\hline & pyrD & & $-2.56(0.08)$ & & & \\
\hline & pyrF & & $-2.56(0.06)$ & & & \\
\hline
\end{tabular}


Table 2. cont.

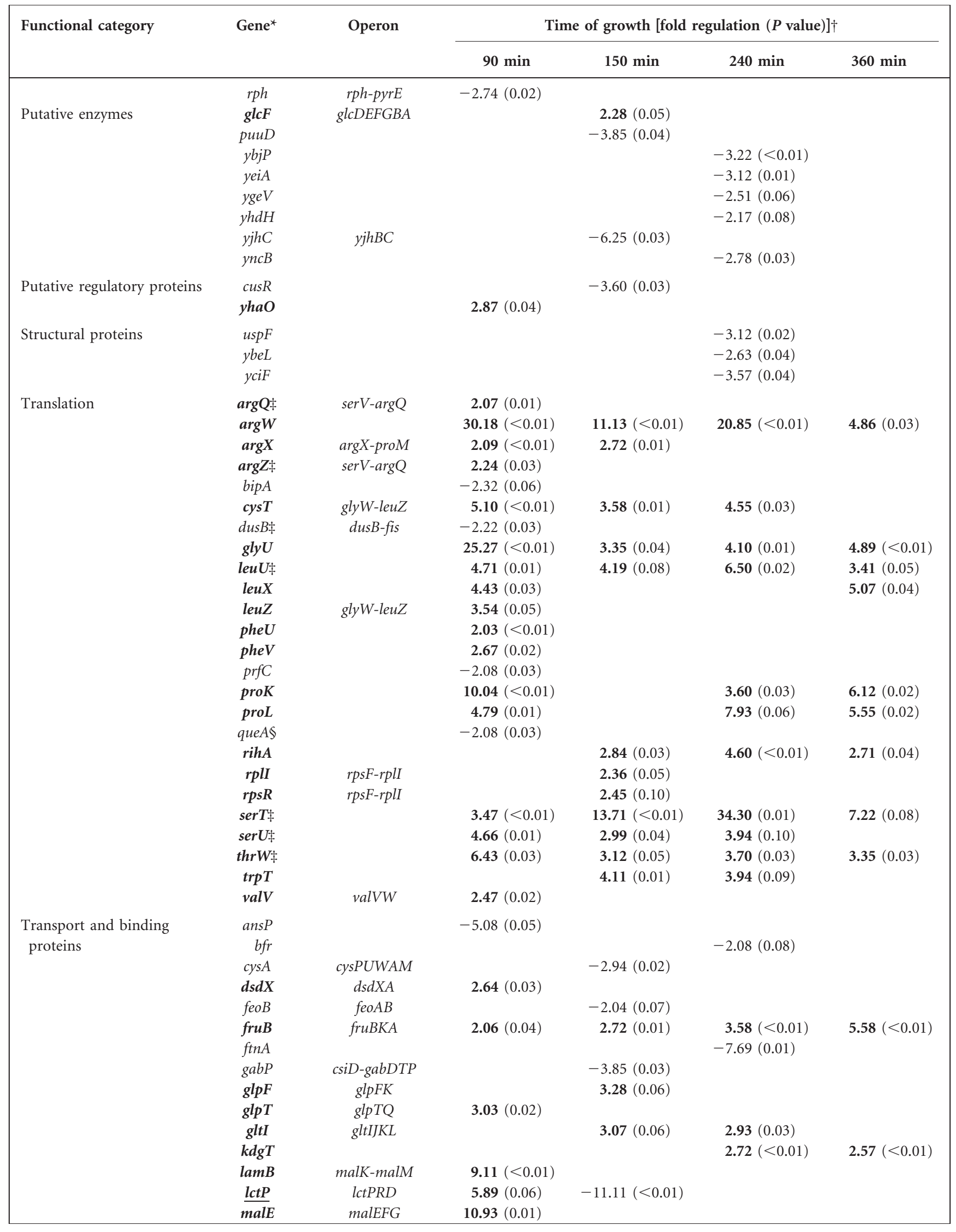


Table 2. cont.

\begin{tabular}{|c|c|c|c|c|c|c|}
\hline \multirow[t]{2}{*}{ Functional category } & \multirow[t]{2}{*}{ Gene $^{*}$} & \multirow[t]{2}{*}{ Operon } & \multicolumn{4}{|c|}{ Time of growth [fold regulation $(P$ value $)] \dagger$} \\
\hline & & & $90 \mathrm{~min}$ & $150 \mathrm{~min}$ & $240 \mathrm{~min}$ & $360 \mathrm{~min}$ \\
\hline & malF & malEFG & $5.60(0.01)$ & & & \\
\hline & malG & malEFG & $5.01(0.04)$ & & & \\
\hline & $\underline{\text { malK }}$ & malK-malM & $18.71(<0.01)$ & & $-2.17(0.05)$ & \\
\hline & $\overline{m s y B}$ & & & & $-2.70(0.02)$ & \\
\hline & $\underline{m t r}$ & & & $-2.38(0.01)$ & $-2.38(0.01)$ & $2.51(0.08)$ \\
\hline & $\overline{\operatorname{narK}}$ & & & & $-5.55(<0.01)$ & \\
\hline & phnC & phnC-P & & $-3.45(0.04)$ & & \\
\hline & proW & proVWX & $4.86(0.01)$ & $-3.22(0.03)$ & & \\
\hline & $\overline{\sec G}$ & & $2.39(<0.01)$ & $2.13(0.02)$ & & \\
\hline & srle & srlA-gutQ & & & $-4.35(0.07)$ & \\
\hline & $t d c C$ & $t d c A-G$ & & & $-2.94(0.02)$ & \\
\hline & $x y l F \neq$ & $x y l F G H R$ & & & $-3.03(0.01)$ & \\
\hline & $y b b M$ & & & $-2.13(0.05)$ & & \\
\hline & yeeF & & $-2.56(<0.01)$ & $2.97(0.06)$ & & \\
\hline & yifK & & $3.46(0.07)$ & & & \\
\hline
\end{tabular}

${ }^{\star}$ Genes showing positive Fis regulation in any of the growth periods are shown in bold type.

$\dagger$ Data from triplicate experiments were merged and the fold Fis regulation is shown. $P$ values obtained from one-way ANOVA are shown in parentheses. Positive regulation is indicated in bold type; negative regulation is indicated with negative values. Genes exhibiting dual regulation are underlined.

$\ddagger$ Genes previously shown to be regulated by Fis in a qualitatively similar manner.

$\$$ Deletion of queA promoter sequences containing two Fis sites resulted in a twofold lower transcription activity, but a definitive Fis-dependent effect was not demonstrated (Slany \& Kersten, 1992).

for low $P$ values (compared to the entire distribution of $P$ values) during two or more stages of growth (Fig. 4b). These included 10 of the 11 functional categories mentioned above. Thus, the global Fis regulatory impact on most of these cellular functions is significant.

There are 18 regulated genes largely within the 'cell processes' category involved in protection against various forms of stress. These include the cold-shock protein genes $\operatorname{csp} I$ and $\operatorname{csp} F$, the universal stress genes $u s p E, u s p F$ and usp $G$, the oxidative stress-response genes $k a t E, k a t G, m s r A$,
sodC and $y \mathrm{kgC}$ (a predicted oxidoreductase), the hyperosmotic stress gene osm $Y$, the multidrug transporter gene emrB, four genes involved in acid resistance, $\operatorname{gad} C$, gadE, $h d e A$ and $h d e B$, and two genes involved in DNA damage repair, tag (encoding 3-methyladenine DNA glycosylase) and ivy (encoding DNA polymerase IV). All these genes display negative regulation by Fis during mid- or late-exponential growth. The oxidative stress gene $a c n B$ (encoding aconitase B) and the osmotically induced osmE have also been shown elsewhere to be negatively regulated by Fis (Bordes et al., 2002; Cunningham et al.,

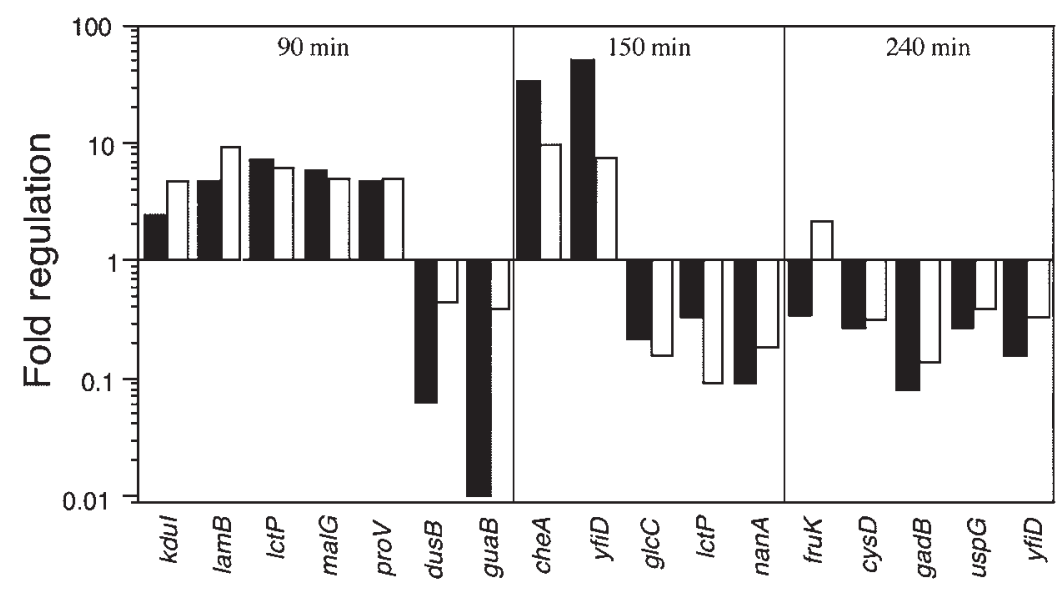

Fis-regulated genes
Fig. 2. Validation of a set of Fis-regulated genes by qRT-PCR. MC1000 and MC1000 fis:: kan cells were grown in LB at $37^{\circ} \mathrm{C}$. Cells were harvested for RNA preparation after 90, 150 and 240 min of growth. qRT-PCR of the indicated mRNAs was performed using equal quantities of RNA samples, normalized by the quantity of rRNA, and shown as a ratio of the WT to the fis signal. Filled bars, fold regulation based on qRT-PCR; open bars, fold regulation based on DNA microarray analysis (Table 2), which is shown for comparison. 


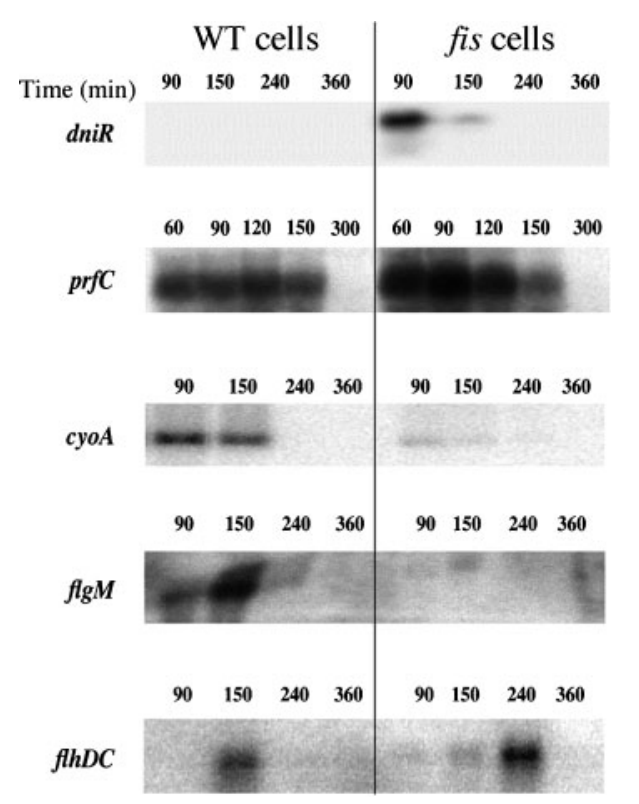

Fig. 3. Northern blot analysis of several Fis-regulated genes. Saturated cultures were diluted 100 -fold in LB, grown at $37^{\circ} \mathrm{C}$, and harvested at the indicated times for the preparation of total RNA. Equal quantities $(10 \mu \mathrm{g})$ of RNA were loaded in each lane and subjected to Northern blot analysis using ${ }^{32} \mathrm{P}$-labelled DNA probes specific for dniR, prfC, cyoA, flgM and flhDC. The prfC mRNA expression pattern was examined in MG1655 and MG1655 fis strains; all other mRNA expression patterns were examined in MC1000 and MC1000 fis strains.

1997). These observations suggest that Fis functions as a general repressor of stress-response genes directly or indirectly.

A set of 17 genes involved in cell motility and chemotaxis (flgB, flgI, flgL, flgM, flgJ, flhA, fliH, fliM, fliM, fliN, fliO, fliQ, fliR, motA, motB, cheW and trg) are positively regulated in the presence of Fis during the mid- or lateexponential growth phase. This suggests a global regulatory role for Fis in stimulating motility and chemotaxis functions, which is in agreement with the previous observation that fis cells are deficient in motility (Osuna et al., 1995). A possible way to achieve the stimulation of the various flagellar genes is to stimulate the expression of flhDC, which encodes the master flagellar gene activator FlhDC (Liu \& Matsumura, 1994). Northern blot analysis showed that Fis affects the temporal expression of $f l h D C$ (Fig. 3). We did not detect high-affinity Fis-binding sites in the $f l h D C$ promoter region based on gel-mobility shift assays (not shown), nor were predicted Fis binding sequences identified in this region, suggesting that the effect of Fis on flhDC expression may be indirect. Nonetheless, the temporal regulatory effect on $f l h D C$ by itself does not adequately account for the Fis-dependent stimulation of flgM mRNA (Fig. 3) and other flagellar genes (Table 2) during the mid- and late-exponential

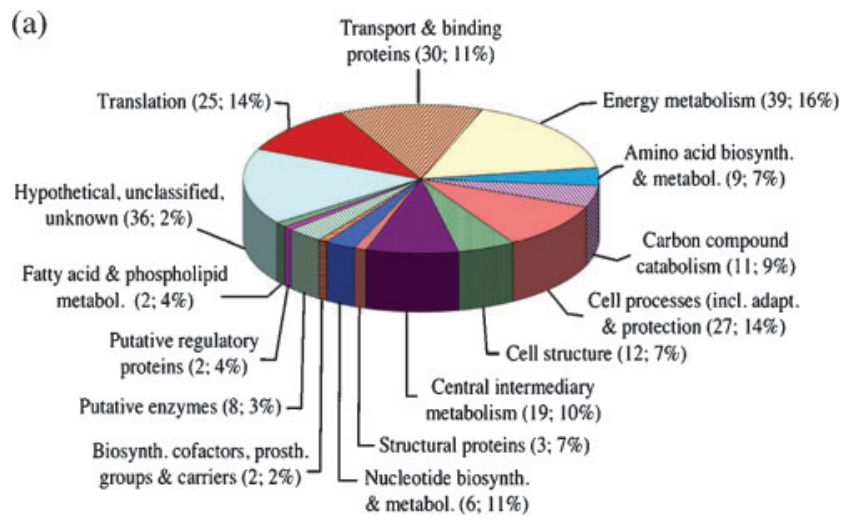

(b)

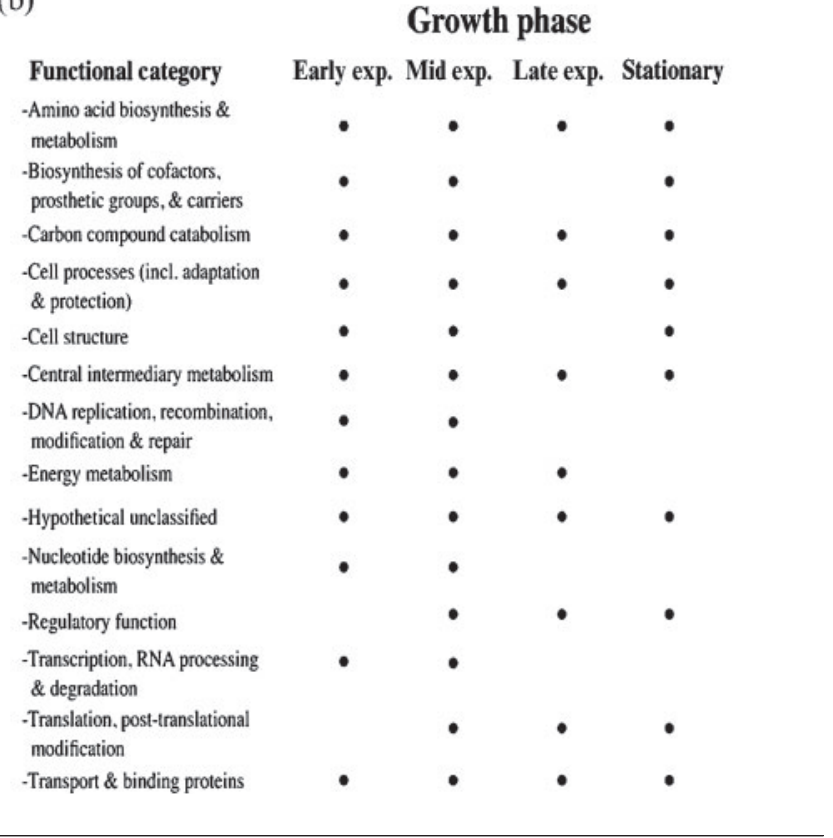

Fig. 4. Functional categorization of Fis-regulated genes. (a) Number of regulated genes per functional category. Genes with a greater than twofold WT : fis signal ratio in the DNA microarray analysis were distributed among the indicated functional categories. The number and percentage of Fis-regulated genes in each functional category is given in parentheses. (b) Functional categories significantly enriched for Fis-regulated genes. Bullets indicate the stage of bacterial growth at which functional categories were found to be significantly enriched $(P \leqslant 0.05)$ for Fis-regulated genes. exp., exponential.

growth phases. Thus, Fis may rely on mechanisms other than the regulation of $f l h D C$ expression to directly or indirectly stimulate flagellar gene expression.

\section{Growth phase regulatory trends}

Despite previous expectations that Fis regulatory effects would be observed primarily during the early exponential growth phase when Fis levels are higher than at later growth periods, regulatory effects were observed during all four stages of growth examined, e.g. 148 genes were 
regulated during the late-exponential growth phase and 24 genes during stationary phase (Fig. 5). During the early exponential growth phase, when cells are initiating logarithmic cell division, Fis acts as a positive regulator of genes involved in translation, transport and binding proteins, carbon compound catabolism, energy metabolism, and central intermediary metabolism (Fig. 5a). Most of the negative regulation at this stage involves genes of unknown function, and genes involved in nucleotide biosynthesis and metabolism. Stimulation of genes involved in carbon catabolism, translation, and transport and binding continued during the mid-exponential growth phase, although several genes involved in transport and binding were repressed (Fig. 5b). A number of cell processes and cell structure genes (mostly flagellar and motility genes) also became stimulated during this stage. During the late-exponential growth phase, there was a dramatic shift in regulation. During this phase, Fis caused repression of 117 genes (Fig. 5c). During early stationary phase, a modest number of genes involved in translation, transport, cell processes (motility), and carbon compound catabolism continued to be upregulated (Fig. 5d).

\section{Putative Fis binding sites within Fis-regulated promoters}

To begin to identify potential Fis targets of direct regulation, we performed a weight matrix-based pattern matching analysis to identify putative Fis binding sites within promoter regions of regulated genes or operons. We retrieved one or more Fis binding sites within 107 of the 168 promoter regions represented in our list. The approach identified previously known Fis binding sites with remarkable precision. For instance, the six experimentally identified Fis binding sites in the fis promoter region (Ball et al., 1992) were retrieved. Moreover, two previously known Fis sites in the aldB promoter region (Xu \& Johnson, 1995b), three binding sites in the $n d h$ promoter (a)

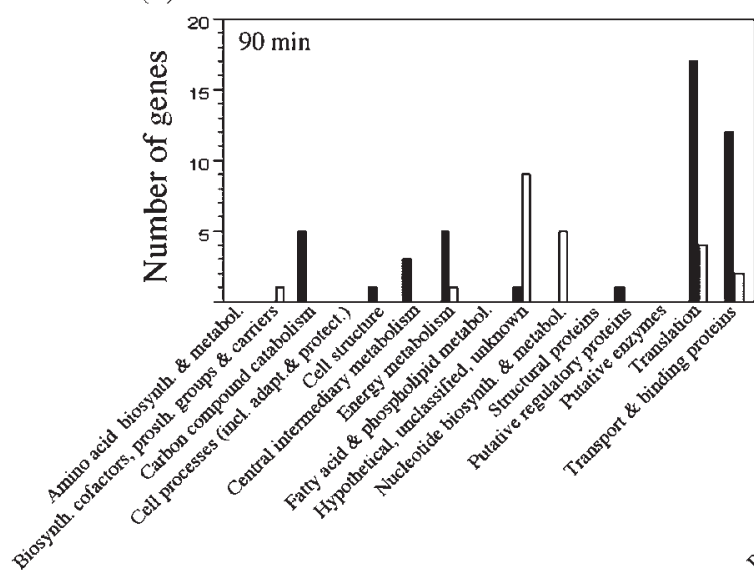

(c)

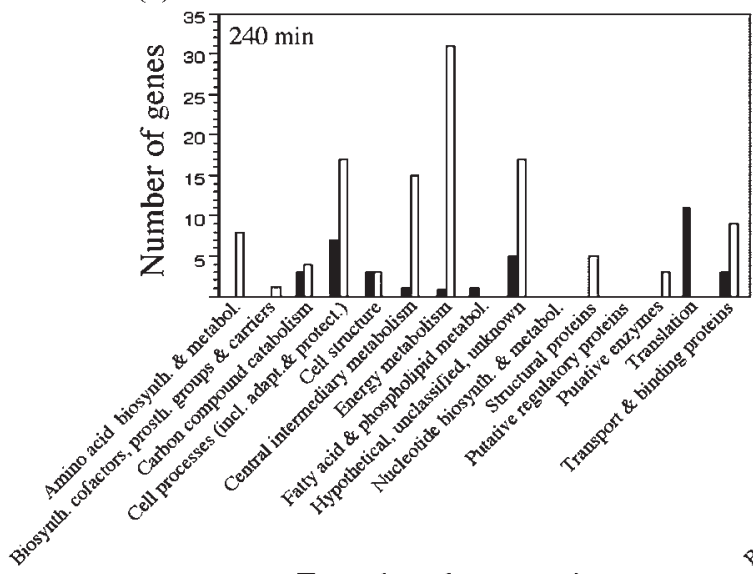

Functional categories (b)

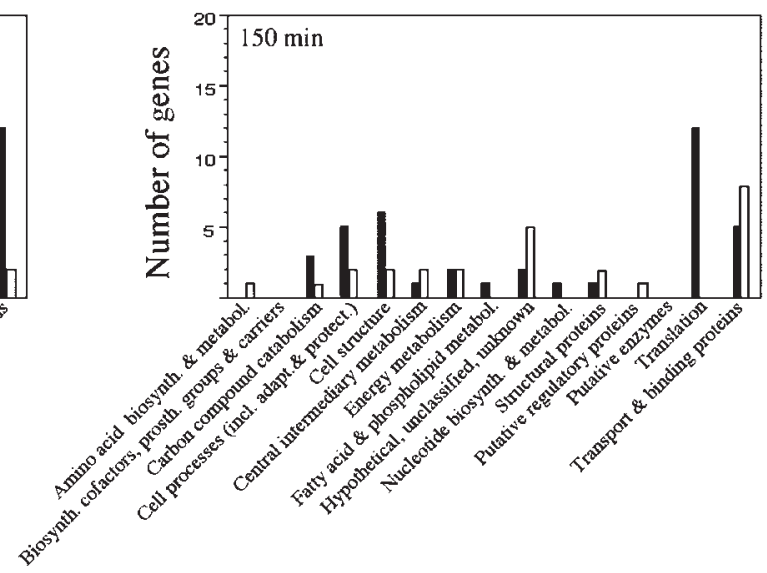

(d)

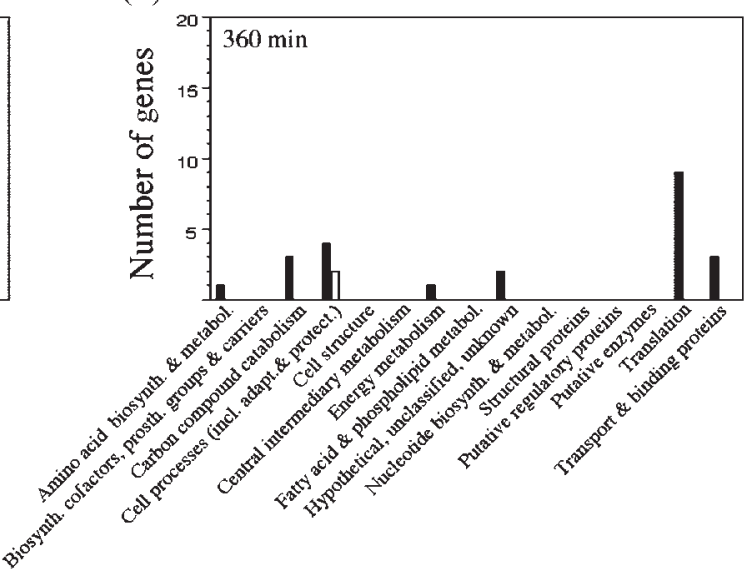

Functional categories

Fig. 5. Growth phase-dependent effects of Fis on functionally categorized genes. The number of regulated genes within the 15 categories is indicated for each of the four periods of growth examined. Filled bars, positively regulated genes; open bars, negatively regulated genes. 
region (Green et al., 1996), three in the nirB promoter region (Browning et al., 2004a), two in the nrfA promoter region (Browning et al., 2005) and one in the prfC promoter region (M. B. Beach and R. Osuna, unpublished results) were all precisely located through this search. In a number of promoters in which the transcription start sites were known, the predicted Fis binding sites mapped within or near the promoter sequences (Fig. 6), suggesting that these promoters are potential targets of direct Fis regulation. Based on these observations, we estimate that over half the Fis-regulated genes or operons reported in this work are likely to involve Fis binding at their respective promoter regions.

\section{DISCUSSION}

\section{Global Fis regulation in E. coli}

Our DNA microarray analysis revealed 231 E. coli genes subject to Fis regulation, directly or indirectly. Combined observations from qRT-PCR, Northern blotting and previously reported Fis-regulated genes corroborate the results from our microarray analysis. Since only 18 of these genes were shown previously to be regulated by Fis, our work adds 223 new genes to the E. coli Fis modulon. When we consider the 33 genes that form the seven rRNA operons, the 11 other tRNA genes and the 55 other structural genes that have been shown previously to be subject to Fis regulation, the E. coli Fis modulon expands to include at least 330 genes. Even this is a conservative number, since there is an undetermined number of additional regulated genes, as shown by the cases of $c y o A$ and $f \lg M$. The regulated promoters extend beyond the $\sigma 70$ family to include members of the $\sigma 28$ (e.g. motABcheAW, flgM and $\operatorname{trg}$ ) and $\sigma 38$ (e.g. emrAB, hdeAB, katE, katG, osm $Y$, proP and wrbA) promoter families.

An earlier DNA microarray analysis of Fis-regulated genes conducted in Salmonella typhimurium reported about 936 ORFs that were regulated twofold or greater during early or late-exponential growth (Kelly et al., 2004). Only 59 of the regulated genes in S. typhimurium appear among the 231 regulated genes in E. coli, leaving 172 E. coli regulated genes that were not reported in S. typhimurium. Moreover, 12 of the 59 genes reported in both bacterial species show opposite regulatory effects, suggesting significant regulatory differences, despite the possession of identical Fis amino acid sequences (Osuna et al., 1995). Some of these differences might be attributed to differences between the two species in the number and positioning of Fis binding sites relative to the regulated promoters. The fis promoter region itself contains one additional Fis binding site in $E$. coli compared to that in S. typhimurium, resulting in a 10 -fold fis autoregulation in the former compared to only a 2.5-fold autoregulation in the latter (Osuna et al., 1995). In addition, higher intracellular Fis levels measured in $S$. typhimurium compared to E. coli grown under the same conditions in LB medium may account for some of the (a)

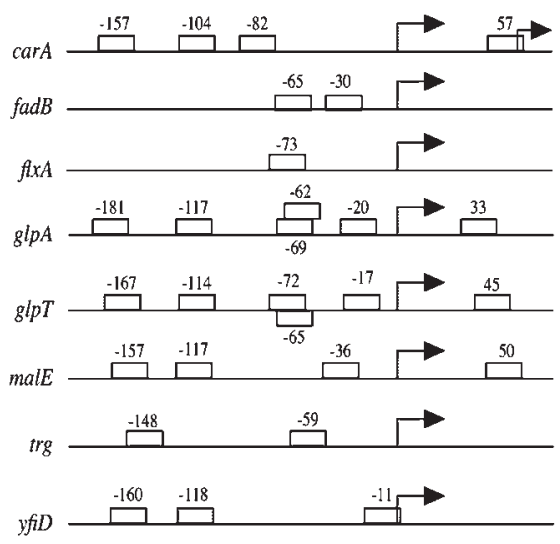

(b)

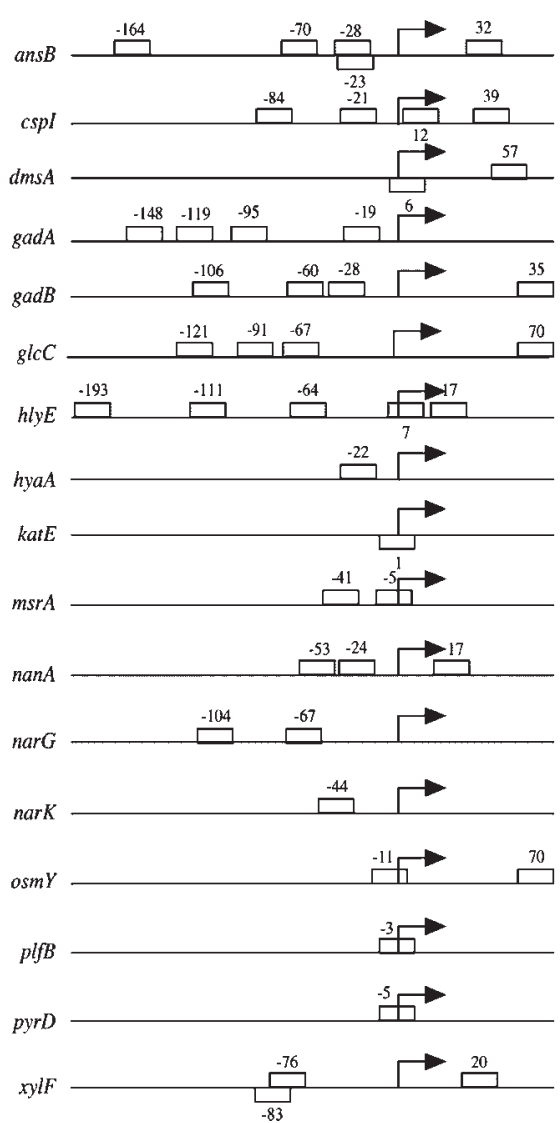

Fig. 6. Prediction of Fis binding sites in Fis-regulated genes. Promoter regions of 25 Fis-regulated genes are schematically represented. Gene names are indicated on the left. Fis sites (open boxes) identified using a weight-matrix pattern search are represented relative to the transcription start sites (arrows) for various (a) positively regulated and (b) negatively regulated genes. The numbers indicate the central position of Fis binding sites relative to the predominant start of transcription.

differences. For example, Fis levels in S. typhimurium have been found to be $\sim 1.75$-fold and $>10$-fold higher than in E. coli during the early exponential growth phase and early 
stationary phase, respectively (Osuna et al., 1995). Promoters relying on relatively weak Fis binding sites for their regulation may be sensitive to these differences in intracellular Fis levels. Differences in Fis concentrations can also give rise to a significant structural reorganization of the bacterial chromatin (Schneider et al., 2001), which can alter the expression of numerous genes (Blot et al., 2006).

Among the most strongly upregulated genes in $S$. typhimurium are 18 flagellar and motility genes (resembling our observations in E. coli) and 79 virulence genes located in the pathogenicity islands SPI-1, SPI-2, SPI-3, SPI-4 and SPI-5. Flagellar genes and genes within the SPI-1 and SPI-2 pathogenicity islands encode three type III secretion systems which are required to mediate virulence (Carsiotis et al., 1984; Hensel, 2000; Mills et al., 1995; Minamino \& Macnab, 1999; Stecher et al., 2004). Thus, Fis seems to play a major role in promoting virulence competency in S. typhimurium. Among the most strongly down-regulated genes are over 50 metabolism and transport genes, an effect that was largely observed during late-exponential to early stationary phase. While we have also observed the repression of certain metabolic and transport genes during the late-exponential growth phase in E. coli, stimulation of numerous other transport and metabolic genes was also observed during the early and mid-exponential growth phases. Therefore, Fis plays an important common role in the regulation of numerous metabolic and transport genes, depending on the growth phase.

\section{Growth phase-dependent gene regulatory effects}

Although most of the Fis regulatory effects occurred during the exponential growth phase, a simple correlation between the growth phase-dependent Fis expression pattern and the number of regulated genes was not observed. Rather, a more complex picture emerged, in which different sets of functionally related genes are coordinately regulated during specified stages of growth, suggesting that Fis is able to regulate related biological processes in accordance with the growth phase (Fig. 7).

Coordinate upregulation of eight operons carrying 38 flagellar and motility genes was prevalent during the midand late-exponential growth phases (Figs 5 and 7). In the case of $f \lg M$, growth phase-dependent stimulation was most dramatic during mid-exponential growth (Fig. 3). Thus, during exponential growth, Fis stimulates flagellar biosynthesis and motility, which provides cells with an ability to explore the environment for available nutrients and to mediate virulence in enteropathogenic strains (Berg, 2003; Giron et al., 2002; La Ragione et al., 2000). Some of the regulated operons (e.g. motABcheAW and flgMN) depend on $\sigma 28$ for their transcription. It will be interesting to determine whether Fis is able to stimulate transcription from such promoters directly and whether novel activation mechanisms are involved.

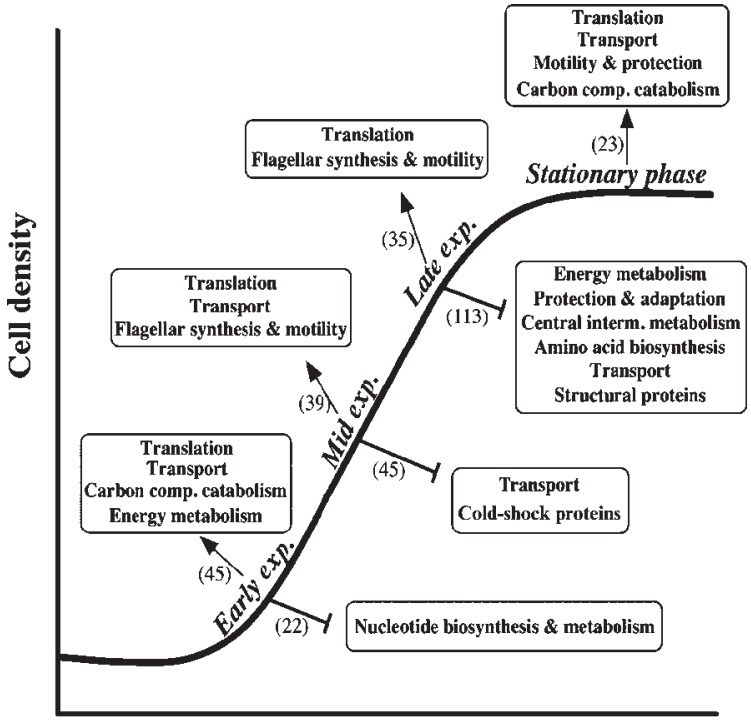

Time

Fig. 7. Fis regulatory trends among functional categories during cell growth. A hypothetical bacterial growth curve is used to illustrate the salient gene categories targeted for Fis regulation during early, mid-, late-exponential and stationary phases. Arrows, positively regulated categories shown above the curve; bars, negatively regulated categories below the curve. The total number of genes observed to be positively or negatively regulated during each growth period is shown in parentheses. comp., compound; interm., intermediary.

Several genes involved in ribonucleotide biosynthesis were collectively repressed during the early exponential growth phase. We and others have shown that the intracellular pool of all four ribonucleotide triphosphates dramatically increases during the outgrowth from stationary phase to the exponential growth phase in rich medium (Murray et al., 2003; Walker et al., 2004). For unknown reasons, the NTP levels transiently decrease about 2.5 -fold soon after the peak of Fis expression. We suggest that the Fisdependent repression of several nucleotide biosynthesis genes during early exponential growth may contribute to the transient drop in NTP levels. This, in turn, is believed to contribute to the decrease in fis transcription, which is hypersensitive to the concentration of CTP (Walker et al., 2004).

In the case of a number of tRNA genes, coordinate upregulation was observed during all stages of growth, although a larger number of them were stimulated during the early exponential growth phase. In addition to the 17 tRNAs reported in this work, 25 tRNA genes and seven rRNA operons are stimulated during the exponential growth phase (Emilsson \& Nilsson, 1995; Hirvonen et al., 2001; Nilsson \& Emilsson, 1994; Nilsson et al., 1990; Ross et al., 1990; Slany \& Kersten, 1992; Verbeek et al., 1992). Thus, our work confirms the notion that Fis exerts a 
concerted effect in upregulating stable RNA genes to help meet the high demand for protein synthesis under fast growth conditions. Interestingly, the bipA gene, which encodes a ribosome-associated protein that facilitates translation of fis (Owens et al., 2004), is repressed during the early exponential growth phase. This suggests that Fis plays a role in controlling its own translation efficiency indirectly by repressing bipA. Translation of other mRNAs may be similarly altered by the repression of $b i p A$. Thus, an appreciation of the full regulatory impact of Fis will likely require a proteomic approach.

A more complex regulatory role was seen for a number of transport genes. Genes involved in the transport of maltose, fructose, glycerol, L-lactate, 2-keto-3-deoxygluconate (KDG), proline, glutamate and general amino acids, and in the type II general secretory pathway, were stimulated during the early exponential growth phase (Fig. 7, Table 2). However, as the growth of the culture advanced through the mid- and late-exponential growth phases, there was a reduction in the number of stimulated transport genes, and an increase in the number of alternative transport and binding genes that were repressed. The latter included genes involved in storing iron, exporting proteins, and transporting xylose, sorbitol, tryptophan, threonine and nitrite. Hence, there was a growth phase-dependent switch in regulatory emphasis from stimulating certain transport functions during the early exponential growth phase to repressing alternative transport and binding functions during the late-exponential growth phase. Sequential changes in the mode of E. coli substrate utilization during growth in the complex LB medium may also trigger a sequential induction of corresponding transport or catabolic systems during different growth stages (Baev et al., 2006). Therefore, some of these changes in transport gene expression might not be observed in a defined growth medium. Nonetheless, our work shows that Fis participates in the regulation of numerous transport genes, thereby affecting substrate availability during different growth stages in LB medium.

A similar switch in regulatory effects was seen for genes involved in carbon compound catabolism, central intermediary metabolism, and energy metabolism. In these functional categories, there was an emphasis on the stimulation of gene expression during early exponential growth, but as cells progressed through the mid- and lateexponential growth phases, there was a shift toward repression of an even larger number of genes. Only a few genes involved in carbon compound catabolism appeared to be regulated during stationary phase.

Surprisingly, as many as 148 genes were found to be regulated during late-exponential growth, of which 113 were repressed. Consistent with these observations, the greatest number of Fis-regulated genes in Salmonella occurs during late-exponential growth (Kelly et al., 2004). The repressed E. coli genes affected a variety of functions, the most salient of which were energy metabolism, stress response (adaptation and protection), central intermediary metabolism, amino acid biosynthesis, transport, and structural proteins. Thus, Fis is somehow involved in decreasing many metabolic processes during late-exponential growth in preparation for stationary phase.

\section{Direct and indirect effects}

Based on in silico identification of Fis binding sites within promoter regions, we estimate that $>60 \%$ of the regulated promoters represented in this study are likely to be directly targeted for Fis regulation. In recent work conducted by Busby and co-corkers (Grainger et al., 2006), chromatin immunoprecipitation combined with high-density microarrays (ChIP-chip) was used to study the binding of Fis, histone-like nucleoid structuring protein ( $\mathrm{H}-\mathrm{NS})$ and integration host factor (IHF) across the E. coli genome in vivo. They identified a large number of DNA binding positions for Fis $(>20000), \sim 50 \%$ of which were located in non-coding DNA, even though non-coding DNA accounts for $<10 \%$ of the E. coli genome. Additionally, they found that $\sim 50 \%$ of the non-coding targets for Fis were also associated with RNAP. These observations suggest a large bias for Fis binding sites within intergenic regions and a possible role in transcription regulation. Using their supplementary data containing the coordinates for the Fis binding sites identified in vivo, we determined that $\sim 85 \%$ of the promoter regions for the Fis-regulated genes or operons identified in our work (Table 2) are targeted for Fis binding in vivo.

We envision that direct Fis-regulatory effects are prominent during the early and mid-exponential growth phases, when higher intracellular Fis levels are measured (Ali Azam et al., 1999; Ball et al., 1992; Nilsson et al., 1992b). These promoters may rely on relatively weak Fis binding sites that would require the very high Fis concentrations normally observed during the early exponential growth phase for effective occupancy. Conversely, when Fis levels are very low during the late-exponential growth and stationary phases, regulation may be achieved through pleiotropic effects, resulting in delayed responses. For instance, combined evidence from our work and that of others shows that Fis mediates the regulation of other transcription regulators, such as GadE, CusR (Table 2), cyclic AMP receptor protein (CRP), H-NS and HU (Claret \& RouviereYaniv, 1996; Falconi et al., 1996; Gonzalez-Gil et al., 1998). This may trigger several gene regulatory cascades that have various delayed gene regulatory effects during stationary phase. We note, for example, that there are 39 Fis-regulated genes or operons listed in Table 2 that have been shown to be regulated by CRP, H-NS or GadE, of which 25 exhibit Fis-regulatory effects during the late-exponential growth phase.

Direct regulation may also be envisioned to occur during the late-exponential growth and early stationary phases in promoters that efficiently recruit Fis, despite its very low levels. For instance, reliance on relatively strong Fis binding 
sites or on cooperative interactions between Fis and other proteins (including RNAP) are conceivable strategies for recruiting Fis when it is present in low concentrations. We have observed that placement of a high-affinity Fis binding site within the spacer region of a promoter confers considerable Fis-dependent repression during both early and late-exponential growth phases, whereas lower-affinity Fis binding sites limit the regulatory effects to the early exponential growth phase (Y. Shao and R. Osuna, unpublished results). There are precedents for Fis involvement in cooperative interactions: with Xis during their binding to the phage $\lambda$ attR region (Numrych et al., 1992; Thompson et al., 1987), and with $\sigma 38$ RNAP during their binding to the proP P2 promoter region (McLeod et al., 1999). In fact, Fis has been shown to play a direct role in stimulating transcription of the RpoS-dependent proP P2 promoter, which is observed during the late-exponential growth and stationary phases when Fis levels are low and RpoS levels are increasing (McLeod et al., 1999, 2002; Xu \& Johnson, 1995a). The high-affinity Fis binding site at -41 , the interactions between Fis and $\alpha$ CTD of RNAP, and the collaboration with CRP at this promoter may all contribute to the effective utilization of Fis, even when its levels are low.

Because Fis is the most abundant nucleoid-associated protein during the exponential growth phase in rich medium, reaching cellular concentrations of $\sim 50 \mu \mathrm{M}$ (Ali Azam et al., 1999; Ball et al., 1992), it is considered to contribute significantly to the topology of the bacterial chromosome. Based on its effects on plasmid topology in vivo, it has been shown that Fis is able to modulate growth phase-dependent transitions in DNA topology (Schneider et al., 1997). This can be accomplished directly by a combination of specific and non-specific DNA binding at micromolar Fis concentrations, resulting in the stabilization of DNA loops and DNA branching to constrain negative supercoils. Such topological effects have been detected by the use of atomic force and electron microscopy (Schneider et al., 2001), discontinuous highforce stretching of single DNA molecules bound by Fis (Skoko et al., 2005), and differential sensitivity to different topoisomerases compatible with a role for Fis in stabilizing DNA loops (Schneider et al., 1997). Fis can also affect DNA supercoiling indirectly, because of its roles in repressing transcription of gyrA and $g y r B$ to reduce the DNA gyrase activity (Schneider et al., 1999), increasing topA transcription to enhance topoisomerase I activity (WeinsteinFischer et al., 2000), and regulating the expression of other DNA-binding proteins such as H-NS, HU and CRP (Claret \& Rouviere-Yaniv, 1996; Falconi et al., 1996; Gonzalez-Gil et al., 1998) that also affect DNA supercoiling directly or indirectly (Broyles \& Pettijohn, 1986; Gomez-Gomez et al., 1996; Tupper et al., 1994). Thus, the dramatic growth phase-dependent Fis expression triggered by a nutritional upshift can bring about a dynamic reorganization of the chromosomal structure that should alter the expression of many genes. During the transition from exponential to stationary phase, when Fis levels are continually declining while elevated levels of the nucleoid-associated proteins Dps, IHF, HU, Hfq and H-NS are maintained (Ali Azam et al., 1999), a global redistribution of chromosomal DNA branching can affect the accessibility of RNAP to numerous promoters to indirectly alter gene expression. Consistent with these views are the results from a recent DNA microarray approach, which combined mutations in fis and hns with induced changes in DNA superhelicity to demonstrate that the gene regulatory profiles in the presence or absence of these proteins are substantially affected by differences in DNA supercoiling levels (Blot et al., 2006).

\section{Fis as a signal for nutritional upshift, stringent response and growth-rate control}

The global regulatory effects observed in this work were triggered by the dramatic growth phase-dependent expression of Fis in response to a nutritional upshift when cells in stationary phase were outgrown in rich medium. Many of the Fis-dependent effects seen here (e.g. upregulation of translation, transport, motility, energy metabolism and carbon catabolism functions) enhance the ability of E. coli to respond efficiently and competitively to a substantial increase in the nutritional supply. Indeed, fis cells are effectively overtaken by WT cells when both are grown together in a chemostat (Nilsson et al., 1992a). Thus, Fis seems to play a widespread role in signalling conditions of high nutritional content and outfitting the cells for efficient nutrient uptake, metabolism, and rapid growth.

On the other hand, Fis can also play a role in signalling poor nutritional conditions. In response to amino acid starvation, fis is subject to severe and rapid negative control of transcription by the stringent response in E. coli (Mallik et al., 2006; Ninnemann et al., 1992), Klebsiella pneumoniae, Serratia marcescens, Erwinia carotovora and Proteus vulgaris (Mallik et al., 2004). We envision that such a severe negative control of fis gives way to upregulation of a large number of negatively regulated genes and to downregulation of positively regulated genes, depending on the growth stage. Consistent with this idea, 21 operons or genes negatively regulated by Fis in our microarray data (bfr, cydAB, frdABCD, ftnA, csiD-gabDTP, hdeAB, hisLGDCBHAFI, hyaABCDEF, msrA, msyB, mtr, narK, $n f r A B C D E F G$, osmE, osmY, phnC-P, ycgB, yeaGH, ygaM, $y h h A$ and $w r b A$ ) are positively regulated by conditions that trigger the stringent response (Chang et al., 2002; Smulski et al., 2001). Conversely, nine positively regulated operons or genes in our microarray data (carAB, flgB-J, fliKL, glpFK, gltIJKL, malEFG, proVWX, rpsFpriBrpsRrplI and $\sec G$ ) are negatively regulated by conditions that induce a stringent response. Hence, Fis may play an important role in amplifying the effects of the stringent response in E. coli and other enteric bacteria.

There are currently two predominant models that explain the positive control of a number of genes by the mediator 
of the stringent response, (p)ppGpp (Cashel et al., 1996). In an indirect model, (p)ppGpp repression of the highly transcribed stable RNA promoters substantially increases the available concentration of RNAP. Promoters with weak RNAP binding affinities $\left(K_{\mathrm{B}}\right)$ are then able to bind RNAP and initiate transcription (Cashel et al., 1996). In a direct model, (p)ppGpp and DksA interact with RNAP to facilitate productive initiation complexes at some promoters (Paul et al., 2005). We suggest that repression of Fis by the stringent control provides another mechanism for the upregulation of a number of genes.

Since Fis is also subject to growth-rate control (Ball et al., 1992; Mallik et al., 2006; Nilsson \& Emilsson, 1994), it may also serve as an effective mediator of the growth-rate control of a number of genes. A role for Fis in mediating growth-rate control has already been proposed for several tRNA genes and for a mutant variant of $r r n B$ P1 (Bartlett et al., 2000; Nilsson \& Emilsson, 1994). fis expression is also controlled by DNA supercoiling (Schneider et al., 2000; Walker et al., 2004), IHF (Pratt et al., 1997) and CRP (Nasser et al., 2001). Thus, as a global gene regulator, Fis is well suited to the amplification of the effects of these cis and trans regulatory factors in response to various environmental signals.

\section{ACKNOWLEDGEMENTS}

We thank Andrew Brooks for conducting microarray hybridizations at the University of Rochester Microarray Core Facility and for guidance in the analysis of the data. We also thank Sridar V. Chittur and John Tine (University at Albany Center for Functional Genomics) for conducting microarray hybridizations and qRT-PCR. We are grateful to Yongping Shao for numerous discussions and assistance in the matrix-based search for Fis binding sites. This work was supported in part through NIH grant GM52051 to R. O. and through a Faculty Research Award to R. O. from the University at Albany.

\section{REFERENCES}

Aiba, H., Adhya, S. \& de Crombrugghe, B. (1981). Evidence for two functional $\mathrm{gal}$ promoters in intact Escherichia coli cells. J Biol Chem 256, 11905-11910.

Ali Azam, T., Iwata, A., Nishimura, A., Ueda, S. \& Ishihama, A. (1999). Growth phase-dependent variation in protein composition of the Escherichia coli nucleoid. J Bacteriol 181, 6361-6370.

Baev, M. V., Baev, D., Radek, A. J. \& Campbell, J. W. (2006). Growth of Escherichia coli MG1655 on LB medium: monitoring utilization of sugars, alcohols, and organic acids with transcriptional microarrays. Appl Microbiol Biotechnol 71, 310-316.

Ball, C. A. \& Johnson, R. C. (1991). Efficient excision of phage lambda from the Escherichia coli chromosome requires the Fis protein. J Bacteriol 173, 4027-4031.

Ball, C. A., Osuna, R., Ferguson, K. C. \& Johnson, R. C. (1992). Dramatic changes in Fis levels upon nutrient upshift in Escherichia coli. J Bacteriol 174, 8043-8056.

Bartlett, M. S., Gaal, T., Ross, W. \& Gourse, R. L. (2000). Regulation of rRNA transcription is remarkably robust: FIS compensates for altered nucleoside triphosphate sensing by mutant RNA polymerases at Escherichia coli rrn P1 promoters. J Bacteriol 182, 1969-1977.
Berg, H. C. (2003). The rotary motor of bacterial flagella. Annu Rev Biochem 72, 19-54.

Blot, N., Mavathur, R., Geertz, M., Travers, A. \& Muskhelishvili, G. (2006). Homeostatic regulation of supercoiling sensitivity coordinates transcription of the bacterial genome. EMBO Rep 7, 710-715.

Bokal, A. J., Ross, W., Gaal, T., Johnson, R. C. \& Gourse, R. L. (1997). Molecular anatomy of a transcription activation patch: FIS-RNA polymerase interactions at the Escherichia coli $\mathrm{rrnB}$ P1 promoter. EMBO J 16, 154-162.

Bordes, P., Bouvier, J., Conter, A., Kolb, A. \& Gutierrez, C. (2002). Transient repressor effect of Fis on the growth phase-regulated osmE promoter of Escherichia coli K12. Mol Genet Genomics 268, 206-213.

Bosch, L., Nilsson, L., Vijgenboom, E. \& Verbeek, H. (1990). FISdependent trans-activation of tRNA and rRNA operons of Escherichia coli. Biochim Biophys Acta 1050, 293-301.

Brazma, A., Hingamp, P., Quackenbush, J., Sherlock, G., Spellman, P., Stoeckert, C., Aach, J., Ansorge, W., Ball, C. A. \& other authors (2001). Minimum information about a microarray experiment (MIAME) toward standards for microarray data. Nat Genet 29, 365-371.

Browning, D. F., Cole, J. A. \& Busby, S. J. (2000). Suppression of FNR-dependent transcription activation at the Escherichia coli nir promoter by Fis, IHF and H-NS: modulation of transcription initiation by a complex nucleo-protein assembly. Mol Microbiol 37, 1258-1269.

Browning, D. F., Cole, J. A. \& Busby, S. J. (2004a). Transcription activation by remodelling of a nucleoprotein assembly: the role of NarL at the FNR-dependent Escherichia coli nir promoter. Mol Microbiol 53, 203-215.

Browning, D. F., Beatty, C. M., Sanstad, E. A., Gunn, K. E., Busby, S. J. $\&$ Wolfe, A. J. (2004b). Modulation of CRP-dependent transcription at the Escherichia coli acs $\mathrm{P} 2$ promoter by nucleoprotein complexes: antiactivation by the nucleoid proteins FIS and IHF. Mol Microbiol 51, 241-254.

Browning, D. F., Grainger, D. C., Beatty, C. M., Wolfe, A. J., Cole, J. A. \& Busby, S. J. (2005). Integration of three signals at the Escherichia coli nrf promoter: a role for Fis protein in catabolite repression. Mol Microbiol 57, 496-510.

Broyles, S. S. \& Pettijohn, D. E. (1986). Interaction of the Escherichia coli HU protein with DNA. Evidence for formation of nucleosomelike structures with altered DNA helical pitch. J Mol Biol 187, 47-60.

Caramel, A. \& Schnetz, K. (2000). Antagonistic control of the Escherichia coli bgl promoter by FIS and CAP in vitro. Mol Microbiol 36, 85-92.

Carsiotis, M., Weinstein, D. L., Karch, H., Holder, I. A. \& O’Brien, A. D. (1984). Flagella of Salmonella typhimurium are a virulence factor in infected C57BL/6J mice. Infect Immun 46, 814-818.

Cashel, M., Gentry, D. R., Hernandez, V. J. \& Vinella, D. (1996). The Stringent Response, 2nd edn. Washington, DC: ASM Press.

Chang, D. E., Smalley, D. J. \& Conway, T. (2002). Gene expression profiling of Escherichia coli growth transitions: an expanded stringent response model. Mol Microbiol 45, 289-306.

Claret, L. \& Rouviere-Yaniv, J. (1996). Regulation of HU alpha and HU beta by CRP and FIS in Escherichia coli. J Mol Biol 263, 126-139.

Cunningham, L., Gruer, M. J. \& Guest, J. R. (1997). Transcriptional regulation of the aconitase genes (acnA and $a c n B$ ) of Escherichia coli. Microbiology 143, 3795-3805.

Emilsson, V. \& Nilsson, L. (1995). Factor for inversion stimulationdependent growth rate regulation of serine and threonine tRNA species. J Biol Chem 270, 16610-16614. 
Falconi, M., Brandi, A., La Teana, A., Gualerzi, C. O. \& Pon, C. L. (1996). Antagonistic involvement of FIS and H-NS proteins in the transcriptional control of hns expression. Mol Microbiol 19, 965-975.

Feng, J.-A., Yuan, H. A., Finkel, S. E., Johnson, R. C., KaczorGrzeskowiak, M. \& Dickerson, R. E. (1992). The interaction of Fis protein with its DNA-binding sequences. In Structure and Function, pp. 1-9. Edited by R. H. Sarma \& M. H. Sarma. Schenectady, NY: Adenine Press.

Filutowicz, M., Ross, W., Wild, J. \& Gourse, R. L. (1992). Involvement of Fis protein in replication of the Escherichia coli chromosome. J Bacteriol 174, 398-407.

Finkel, S. E. \& Johnson, R. C. (1992). The Fis protein: it's not just for DNA inversion anymore. Mol Microbiol 6, 3257-3265.

Giron, J. A., Torres, A. G., Freer, E. \& Kaper, J. B. (2002). The flagella of enteropathogenic Escherichia coli mediate adherence to epithelial cells. Mol Microbiol 44, 361-379.

Goh, E. B., Yim, G., Tsui, W., McClure, J., Surette, M. G. \& Davies, J. (2002). Transcriptional modulation of bacterial gene expression by subinhibitory concentrations of antibiotics. Proc Natl Acad Sci U S A 99, 17025-17030.

Gomez-Gomez, J. M., Baquero, F. \& Blazquez, J. (1996). Cyclic AMP receptor protein positively controls gyrA transcription and alters DNA topology after nutritional upshift in Escherichia coli. J Bacteriol 178, 3331-3334.

Gonzalez-Gil, G., Bringmann, P. \& Kahmann, R. (1996). FIS is a regulator of metabolism in Escherichia coli. Mol Microbiol 22, 21-29.

Gonzalez-Gil, G., Kahmann, R. \& Muskhelishivili, G. (1998). Regulation of $\operatorname{crp}$ transcription by oscillation between distinct nucleoprotein complexes. EMBO J 17, 2877-2885.

Gosink, K. K., Gaal, T., Bokal, A. J., IV \& Gourse, R. L. (1996). A positive control mutant of the transcription activator protein FIS. J Bacteriol 178, 5182-5187.

Grainger, D. C., Hurd, D., Goldberg, M. D. \& Busby, S. J. (2006). Association of nucleoid proteins with coding and non-coding segments of the Escherichia coli genome. Nucleic Acids Res 34, 4642-4652.

Green, J., Anjum, M. F. \& Guest, J. R. (1996). The $n d h$-binding protein $(\mathrm{Nbp})$ regulates the $n d h$ gene of Escherichia coli in response to growth phase and is identical to Fis. Mol Microbiol 20, 1043-1055.

Grunsky, E. C. (2002). R: a Data Analysis and Statistical Programming Environment - an Emerging Tool for the Geosciences. Tarrytown, NY: Pergamon Press.

Haffter, P. \& Bickle, T. A. (1987). Purification and DNA-binding properties of FIS and Cin, two proteins required for the bacteriophage P1 site-specific recombination system, cin. J Mol Biol 198, 579-587.

Hengen, P. N., Bartram, S. L., Stewart, L. E. \& Schneider, T. D. (1997). Information analysis of Fis binding sites. Nucleic Acids Res 25, 4994-5002.

Hensel, M. (2000). Salmonella pathogenicity island 2. Mol Microbiol 36, 1015-1023.

Hirvonen, C. A., Ross, W., Wozniak, C. E., Marasco, E., Anthony, J. R., Aiyar, S. E., Newburn, V. H. \& Gourse, R. L. (2001). Contributions of UP elements and the transcription factor FIS to expression from the seven rrn P1 promoters in Escherichia coli. J Bacteriol 183, 6305-6314.

Ikaka, R. \& Gentleman, R. (1996). R: a language for data analysis and graphics. J Comput Graph Stat 5, 299-314.

Jacobson, B. A. \& Fuchs, J. A. (1998). Multiple cis-acting sites positively regulate Escherichia coli nrd expression. Mol Microbiol 28, 1315-1322.

Johnson, R. C., Bruist, M. F. \& Simon, M. I. (1986). Host protein requirements for in vitro site-specific DNA inversion. Cell 46, 531-539.
Johnson, R. C., Ball, C. A., Pfeffer, D. \& Simon, M. I. (1988). Isolation of the gene encoding the Hin recombinational enhancer binding protein. Proc Natl Acad Sci U S A 85, 3484-3488.

Kahmann, R., Rudt, F., Koch, C. \& Mertens, G. (1985). G inversion in bacteriophage $\mathrm{Mu}$ DNA is stimulated by a site within the invertase gene and a host factor. Cell 41, 771-780.

Keane, O. M. \& Dorman, C. J. (2003). The gyr genes of Salmonella enterica serovar Typhimurium are repressed by the factor for inversion stimulation, Fis. Mol Genet Genomics 270, 56-65.

Kelly, A., Goldberg, M. D., Carroll, R. K., Danino, V., Hinton, J. C. \& Dorman, C. J. (2004). A global role for Fis in the transcriptional control of metabolism and type III secretion in Salmonella enterica serovar Typhimurium. Microbiology 150, 2037-2053.

La Ragione, R. M., Sayers, A. R. \& Woodward, M. J. (2000). The role of fimbriae and flagella in the colonization, invasion and persistence of Escherichia coli O78: K80 in the day-old-chick model. Epidemiol Infect 124, 351-363.

Liu, X. \& Matsumura, P. (1994). The FlhD/FlhC complex, a transcriptional activator of the Escherichia coli flagellar class II operons. J Bacteriol 176, 7345-7351.

Mallik, P., Pratt, T. S., Beach, M. B., Bradley, M. D., Undamatla, J. \& Osuna, R. (2004). Growth phase-dependent regulation and stringent control of fis are conserved processes in enteric bacteria and involve a single promoter (fis P) in Escherichia coli. J Bacteriol 186, 122-135.

Mallik, P., Paul, B. J., Rutherford, S. T., Gourse, R. L. \& Osuna, R. (2006). DksA is required for growth phase-dependent regulation, growth rate-dependent control, and stringent control of fis expression in Escherichia coli. J Bacteriol 188, 5775-5782.

McLeod, S. M., Xu, J., Cramton, S. E., Gaal, T., Gourse, R. L. \& Johnson, R. C. (1999). Localization of amino acids required for Fis to function as a class II transcriptional activator at the RpoS-dependent proP P2 promoter. J Mol Biol 294, 333-346.

McLeod, S. M., Aiyar, S. E., Gourse, R. L. \& Johnson, R. C. (2002). The C-terminal domains of the RNA polymerase alpha subunits: contact site with Fis and localization during co-activation with CRP at the Escherichia coli proP P2 promoter. J Mol Biol 316, $517-529$.

Messer, W., Egan, B., Gille, H., Holz, A., Schaefer, C. \& Woelker, B. (1991). The complex of oriC DNA with the DnaA initiator protein. Res Microbiol 142, 119-125.

Mills, D. M., Bajaj, V. \& Lee, C. A. (1995). A $40 \mathrm{~kb}$ chromosomal fragment encoding Salmonella typhimurium invasion genes is absent from the corresponding region of the Escherichia coli K-12 chromosome. Mol Microbiol 15, 749-759.

Minamino, T. \& Macnab, R. M. (1999). Components of the Salmonella flagellar export apparatus and classification of export substrates. $J$ Bacteriol 181, 1388-1394.

Murray, H. D., Schneider, D. A. \& Gourse, R. L. (2003). Control of rRNA expression by small molecules is dynamic and nonredundant. Mol Cell 12, 125-134.

Muskhelishvili, G., Buckle, M., Heumann, H., Kahmann, R. \& Travers, A. A. (1997). FIS activates sequential steps during transcription initiation at a stable RNA promoter. EMBO J 16, 3655-3665.

Nasser, W., Schneider, R., Travers, A. \& Muskhelishvili, G. (2001). CRP modulates fis transcription by alternate formation of activating and repressing nucleoprotein complexes. J Biol Chem 276, 1787817886.

Nilsson, L. \& Emilsson, V. (1994). Factor for inversion stimulationdependent growth rate regulation of individual tRNA species in Escherichia coli. J Biol Chem 269, 9460-9465. 
Nilsson, L., Vanet, A., Vijgenboom, E. \& Bosch, L. (1990). The role of FIS in trans activation of stable RNA operons of E. coli. EMBO J $\mathbf{9}$, 727-734.

Nilsson, L., Verbeek, H., Hoffmann, U., Haupt, M. \& Bosch, L. (1992a). Inactivation of the fis gene leads to reduced growth rate. FEMS Microbiol Lett 78, 85-88.

Nilsson, L., Verbeek, H., Vijgenboom, E., van Drunen, C., Vanet, A. \& Bosch, L. (1992b). FIS-dependent trans activation of stable RNA operons of Escherichia coli under various growth conditions. J Bacteriol 174, 921-929.

Ninnemann, O., Koch, C. \& Kahmann, R. (1992). The E. coli fis promoter is subject to stringent control and autoregulation. EMBO J 11, 1075-1083.

Numrych, T. E., Gumport, R. I. \& Gardner, J. F. (1992). Characterization of the bacteriophage lambda excisionase (Xis) protein: the C-terminus is required for Xis-integrase cooperativity but not for DNA binding. EMBO J 11, 3797-3806.

Opel, M. L., Aeling, K. A., Holmes, W. M., Johnson, R. C., Benham, C. J. \& Hatfield, G. W. (2004). Activation of transcription initiation from a stable RNA promoter by a Fis protein-mediated DNA structural transmission mechanism. Mol Microbiol 53, 665-674.

Osuna, R., Lienau, D., Hughes, K. T. \& Johnson, R. C. (1995). Sequence, regulation, and functions of fis in Salmonella typhimurium. J Bacteriol 177, 2021-2032.

Owens, R. M., Pritchard, G., Skipp, P., Hodey, M., Connell, S. R., Nierhaus, K. H. \& O'Connor, C. D. (2004). A dedicated translation factor controls the synthesis of the global regulator Fis. EMBO J 23, 3375-3385.

Paul, B. J., Berkmen, M. B. \& Gourse, R. L. (2005). DksA potentiates direct activation of amino acid promoters by ppGpp. Proc Natl Acad Sci U S A 102, 7823-7828.

Pease, A. J., Roa, B. R., Luo, W. \& Winkler, M. E. (2002). Positive growth rate-dependent regulation of the $p d x A, k s g A$, and $p d x B$ genes of Escherichia coli K-12. J Bacteriol 184, 1359-1369.

Pratt, T. S., Steiner, T., Feldman, L. S., Walker, K. A. \& Osuna, R. (1997). Deletion analysis of the fis promoter region in Escherichia coli: antagonistic effects of integration host factor and Fis. J Bacteriol 179, 6367-6377.

Ross, W., Thompson, J. F., Newlands, J. T. \& Gourse, R. L. (1990). E. coli Fis protein activates ribosomal RNA transcription in vitro and in vivo. EMBO J 9, 3733-3742.

Ryan, V. T., Grimwade, J. E., Camara, J. E., Crooke, E. \& Leonard, A. C. (2004). Escherichia coli prereplication complex assembly is regulated by dynamic interplay among Fis, IHF and DnaA. Mol Microbiol 51, $1347-1359$.

Sambrook, J. E., Fritsch, E. F. \& Maniatis, T. (1989). Molecular Cloning: a Laboratory Manual, 2nd edn. Cold Spring Harbor, NY: Cold Spring Harbor Laboratory.

Schneider, R., Travers, A. \& Muskhelishvili, G. (1997). FIS modulates growth phase-dependent topological transitions of DNA in Escherichia coli. Mol Microbiol 26, 519-530.

Schneider, R., Travers, A., Kutateladze, T. \& Muskhelishvili, G. (1999). A DNA architectural protein couples cellular physiology and DNA topology in Escherichia coli. Mol Microbiol 34, 953-964.

Schneider, R., Travers, A. \& Muskhelishvili, G. (2000). The expression of the Escherichia coli fis gene is strongly dependent on the superhelical density of DNA. Mol Microbiol 38, 167-175.

Schneider, R., Lurz, R., Luder, G., Tolksdorf, C., Travers, A. \& Muskhelishvili, G. (2001). An architectural role of the Escherichia coli chromatin protein FIS in organising DNA. Nucleic Acids Res 29, $5107-5114$.
Shin, D., Cho, N., Heu, S. \& Ryu, S. (2003). Selective regulation of $p t s G$ expression by Fis. Formation of either activating or repressing nucleoprotein complex in response to glucose. J Biol Chem 278, 14776-14781.

Skoko, D., Yan, J., Johnson, R. C. \& Marko, J. F. (2005). Low-force DNA condensation and discontinuous high-force decondensation reveal a loop-stabilizing function of the protein Fis. Phys Rev Lett 95, 208101.

Slany, R. K. \& Kersten, H. (1992). The promoter of the $t g t / s e c$ operon in Escherichia coli is preceded by an upstream activation sequence that contains a high affinity FIS binding site. Nucleic Acids Res 20, 4193-4198.

Smulski, D. R., Huang, L. L., McCluskey, M. P., Reeve, M. J., Vollmer, A. C., Van Dyk, T. K. \& LaRossa, R. A. (2001). Combined, functional genomic-biochemical approach to intermediary metabolism: interaction of acivicin, a glutamine amidotransferase inhibitor, with Escherichia coli K-12. J Bacteriol 183, 3353-3364.

Sokal, R. R. \& Rohlf, F. J. (1995). Biometry: the Principles and Practice of Statistics in Biological Research. New York: W. H. Freeman.

Stecher, B., Hapfelmeier, S., Muller, C., Kremer, M., Stallmach, T. \& Hardt, W. D. (2004). Flagella and chemotaxis are required for efficient induction of Salmonella enterica serovar Typhimurium colitis in streptomycin-pretreated mice. Infect Immun 72, 4138-4150.

Thompson, J. F., Moitoso de Vargas, L., Koch, C., Kahmann, R. \& Landy, A. (1987). Cellular factors couple recombination with growth phase: characterization of a new component in the lambda sitespecific recombination pathway. Cell 50, 901-908.

Travers, A., Schneider, R. \& Muskhelishvili, G. (2001). DNA supercoiling and transcription in Escherichia coli: the FIS connection. Biochimie 83, 213-217.

Tupper, A. E., Owen-Hughes, T. A., Ussery, D. W., Santos, D. S., Ferguson, D. J., Sidebotham, J. M., Hinton, J. C. \& Higgins, C. F. (1994). The chromatin-associated protein H-NS alters DNA topology in vitro. EMBO J 13, 258-268.

Verbeek, H., Nilsson, L. \& Bosch, L. (1992). The mechanism of transactivation of the Escherichia coli operon $\operatorname{th} U(\operatorname{tufB})$ by the protein FIS. A model. Nucleic Acids Res 20, 4077-4081.

Walker, K. A., Atkins, C. L. \& Osuna, R. (1999). Functional determinants of the Escherichia coli fis promoter: roles of $-35,-10$, and transcription initiation regions in the response to stringent control and growth phase-dependent regulation. J Bacteriol 181, 1269-1280.

Walker, K. A., Mallik, P., Pratt, T. S. \& Osuna, R. (2004). The Escherichia coli fis promoter is regulated by changes in the levels of its transcription initiation nucleotide CTP. J Biol Chem 279, 50818-50828.

Weinreich, M. D. \& Reznikoff, W. S. (1992). Fis plays a role in $\operatorname{Tn} 5$ and IS50 transposition. J Bacteriol 174, 4530-4537.

Weinstein-Fischer, D., Elgrably-Weiss, M. \& Altuvia, S. (2000). Escherichia coli response to hydrogen peroxide: a role for DNA supercoiling, topoisomerase I and Fis. Mol Microbiol 35, 1413-1420.

Winer, J., Jung, C. K., Shackel, I. \& Williams, P. M. (1999). Development and validation of real-time quantitative reverse transcriptase-polymerase chain reaction for monitoring gene expression in cardiac myocytes in vitro. Anal Biochem 270, 41-49.

Wold, S., Crooke, E. \& Skarstad, K. (1996). The Escherichia coli Fis protein prevents initiation of DNA replication from oriC in vitro. Nucleic Acids Res 24, 3527-3532.

Wu, F., Wu, J., Ehley, J. \& Filutowicz, M. (1996). Preponderance of Fisbinding sites in the R6K gamma origin and the curious effect of the penicillin resistance marker on replication of this origin in the absence of Fis. J Bacteriol 178, 4965-4974.

Xu, J. \& Johnson, R. C. (1995a). Fis activates the RpoS-dependent stationary-phase expression of proP in Escherichia coli. J Bacteriol 177, 5222-5231. 
Xu, J. \& Johnson, R. C. (1995b). aldB, an RpoS-dependent gene in Escherichia coli encoding an aldehyde dehydrogenase that is repressed by Fis and activated by CRP. J Bacteriol 177, 3166-3175.

Xu, J. \& Johnson, R. C. (1995c). Identification of genes negatively regulated by Fis: Fis and RpoS comodulate growth-phase-dependent gene expression in Escherichia coli. J Bacteriol 177, 938-947.
Zhi, H., Wang, X., Cabrera, J. E., Johnson, R. C. \& Jin, D. J. (2003). Fis stabilizes the interaction between RNA polymerase and the ribosomal promoter $r r n B$ P1, leading to transcriptional activation. J Biol Chem 278, 47340-47349.

Edited by: W. Margolin 